\title{
Arabic Natural Language Processing for Qur'anic Research: A Systematic Review
}

\author{
Muhammad Huzaifa Bashir ${ }^{1}$, Aqil M. Azmi ${ }^{2}$, Haq Nawaz ${ }^{3}$, Wajdi Zaghouani ${ }^{4}$, Mona Diab ${ }^{5}$, Ala Al-Fuqaha ${ }^{6}$, \\ Junaid Qadir ${ }^{7}$
}

\begin{abstract}
The Qur'an, the holy divine book of Muslims, was revealed over fourteen centuries ago, in Arabic. With the rise of Islam, the Arabic language gained popularity and became the lingua franca for large swaths of the old world. Devout Muslims read the Qur'an on a daily basis seeking guidance and comfort. Though Qur'an, as a text, is short, there is a huge volume of supporting work filling tens of thousands of volumes, e.g., commentaries, exegesis, etc. Recently, there has been a renewed interest by non-specialists. Many of which were fueled by the recent advances in computational and natural language processing (NLP) techniques. These techniques help the development of tools that benefit common people to gain guidance and knowledge easily. This paper aims to survey the different efforts behind the field of Qur'anic NLP. The research work varies from automated morphological analysis to correction of Qur'anic recitation via speech recognition. Multiple approaches have been discussed for a particular task. The paper also discusses the techniques adopted and the tools used for the Qur'anic NLP tasks. In the end, we outline future research directions in this field.
\end{abstract}

Index Terms-Arabic Natural Language Processing, Natural Language Processing, Qur'anic NLP

\section{INTRODUCTION}

The Qur'an is the central religious text of Islam, where Muslims believe it was revealed in the Arabic language to Prophet Muhammad (PBUH $)^{1}$ over a span of twenty-three years that ended in 632CE, the year the Prophet passed away. The word qur'an appears about 70 times in the Qur'an itself, assuming various meanings. It is a verbal noun of the Arabic verb qara'a meaning "he read" or "he recited", an opinion backed by most of the Muslim authorities on the origin of the name Qur'an.

\footnotetext{
${ }^{1}$ M. H. Bashir is with the Department of Electrical Engineering, Information Technology University (ITU), Lahore, Pakistan.

${ }^{2}$ A.M. Azmi is with the Department of Computer Science, College of Computer \& Information Sciences, King Saud University (KSU), Riyadh 11543, Saudi Arabia.

${ }^{3} \mathrm{H}$. Nawaz is with Jamia Ashrafia, Lahore, Pakistan, and the Punjab University College of Information Technology (PUCIT), Lahore, Pakistan.

${ }^{4} \mathrm{~W}$. Zaghouani is with the College of Humanities and Social Sciences, Hamad Bin Khalifa University (HBKU), Doha, Qatar.

${ }^{5} \mathrm{M}$. Diab is with the Department of Computer Science, George Washington University (GW), Washington DC., USA.

${ }^{6} \mathrm{~A}$. Al-Fuqaha is with the Information and Computing Technology Division, College of Science and Engineering, Hamad Bin Khalifa University (HBKU), Doha, Qatar.

${ }^{7} \mathrm{~J}$. Qadir is with the Department of Electrical Engineering, Information Technology University (ITU), Lahore, Pakistan. Corresponding Email: junaid.qadireitu.edu.pk

${ }^{1}$ In line with the Islamic tradition, the name of Prophet Muhammad and other Prophets are affixed with traditional salutations "peace be upon him" (PBUH)
}

The Qur'an was revealed in Arabic, and it is recited in Arabic. This explains why Arabic is the liturgical language of approximately 1.8 billion Muslims, the majority of which are non-Arabs (about $73 \%)^{2}$ Knowing the Arabic language helps them understand the true message of the Qur'an. For Qur' an holds a lot of knowledge and information for mankind, and that knowledge is delivered through crisp and to the point verses in Arabic. Hence the popularity of the Arabic language especially among the Muslims.

Ever since the Qur'an was revealed, thousands of scholars dedicated their lifetime studying Qur'anic scripture from different angles producing knowledge that easily fills tens of thousands of printed volumes. However, past efforts were manual in nature. With the advanced in computational techniques, especially in the field of natural language processing (NLP), we can use NLP techniques for Qur' anic research and develop new applications that can help those interested in learning and understanding the message of the Qur'an.

\section{A. Arabic language and Arabic NLP}

Arabic is a Semitic language that first emerged in the first to fourth centuries $\mathrm{CE}$. This is testified by the various Arabic inscriptions found in the region from that era [1, pp. 126129]. Modern linguists designate Arabic into one of three main classes: Classical, Modern (or MSA, short for Modern Standard Arabic) and Dialectal Arabic. The Standard Arabic is a "prescriptive" term of the language which the early Arab grammarians considered "Classical", while the MSA is a "descriptive" term of realizing Standard Arabic by modern day Arabs. There is a false impression that MSA is the language which has evolved from Standard Arabic, or even Classical Arabic. From a naming point of view, MSA is a misnomer: there has not been modern standardization of the Arabic language, nor did it develop from the older Standard Arabic. Vocabulary wise we can safely assert that MSA is a superset of Classical and Standard Arabic [2]. It is a superset in the sense that MSA incorporates the names of modern inventions, e.g., radio, computer, while retaining the sentence structure and the vocabulary of its classical and standard form. Prof. Bellamy insists that the Arabic inscription at Jabal Ramm (in modern day Jordan), believed to be from the fourth century CE, is closer to modern day Arabic than Shakespeare's language to modern English [3, 4]. It is not unusual to see elementary level Arab children read flawlessly and grasp large part of the message of the Qur'an with very little effort.

\footnotetext{
${ }^{2}$ https://en.wikipedia.org/wiki/Islam_by_country.
} 
TABLE I: The basic Arabic diacritics grouped into three sets. The nunation can only be placed at the end of the word. The syllabification mark shaddah only occurs with either short vowel or nunation.

\begin{tabular}{|c|c|c|c|}
\hline Diacritic Set & $\begin{array}{c}\text { Diacritic on } \\
\text { letter }\end{array}$ & Name & Pronunciation \\
\hline \multirow[t]{3}{*}{ Short vowels } & بَب & fatha & $/ \mathrm{b} / / \mathrm{a} /$ \\
\hline & بُبُ & damma & $/ \mathrm{b} / / \mathrm{u} /$ \\
\hline & بِ & kasra & $/ \mathrm{b} / / \mathrm{i} /$ \\
\hline \multirow[t]{3}{*}{ Nunation } & بَب & tanween fath & /b//an/ \\
\hline & بِّ & tanween damm & /b//un/ \\
\hline & 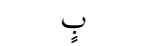 & tanween kasr & /b//in/ \\
\hline \multirow[t]{2}{*}{ Syllabification marks } & بَ & sukon & $/ \mathrm{b} /$ \\
\hline & 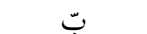 & shaddah & $/ \mathrm{b} / / \mathrm{b} /$ \\
\hline
\end{tabular}

The Arabic language alphabet consists of 25 consonants and three long vowels. It is written from right-to-left in a complex cursive script that permits variable degree of stretching or compressing [5]. Most of the characters assume up to four forms per letter, which are contextually shaped. Additionally, the orthographic system uses a total of thirteen different diacritical markings to represent short vowels $(a, i, u)$, and these are placed either above or below the character (see Table I).

One of the remarkable features of the Arabic language is its expressiveness. For instance, the single word فأسقينا كموه, which appears in the Qur'an (15:22), is equivalent in translation to the complete sentence "and We have given it to you to drink". Arabic morphology is highly complex and yet systematic. The Arabic words are derived from a root word mainly triliteral, which holds the base meaning of the word. Putting these root letters into patterns will morph the meaning of the root creating a set of related words, call stem. We may then append prefixes (e.g., articles, prepositions) and suffixes (linked pronouns) [2]. Thus, the Arabic language can convey a complete and comprehensive message in just a few words.

NLP is a technique to make computers mechanically process and possibly understand the human (natural) language. With over fifty years of research behind NLP, the field has achieved reasonable maturity. This is particularly true for the English language, for all the obvious reasons. Other languages lag behind with varying degree. When compared to the English language, Arabic NLP is at least a decade behind. We may attribute this to the rich nature of the Arabic language and its complex grammatical and syntactic structures. Farghaly and
Shaalan [6] detailed some challenges and problems that have to be tackled while performing NLP tasks related to MSA. Most of the work on Arabic NLP involves MSA, the most widespread and literary form of Arabic.

Salloum et al. [7] noted, a lot of information could be gathered through computational text mining in Arabic literature but the effort in this field is below expectations. This is due to the formidable challenges involved in doing Arabic NLP research. In what follows, we discuss briefly some of the challenges involved in doing Arabic NLP research.

- There is no capitalization in the Arabic script. This makes it hard to identify proper names and further complicates the process of named entity recognition (NER), a basic NLP task.

- The diacritics adds sense and meaning to a word, and the lack of it creates ambiguity. For example, the undiacritized word عـــ could be "contract", "necklace", "to make it complex," etc. [3]. However, have the word been properly diacritized there would not have been any confusion. Unfortunately, the writing custom in MSA is devoid of any diacritical marking. It assumes the reader can disambiguate the meaning through context. This is a false premise. Azmi and Almajed [8] presented a sample sentence which requires world knowledge to disambiguate its true meaning.

- Habash [9] described the problem that is faced during the translation from Arabic as its sentence structure is totally different and the translated sentence has then to be structured properly to make some sense.

\section{B. Unique challenges in Qur'anic Arabic NLP}

When it comes to Qur'an-in addition to the challenges in doing basic Arabic NLP research highlighted previously-a gamut of new challenges arise. For instance, the text of the Qur'an has its own orthography (spelling convention) which differs even from Classical Arabic. Figure 1 shows a verse of the Qur'an. Anyone who has a slight knowledge of Arabic can easily tell the present day spelling of the second word should be أنزلنـاه, the spelling of the rest of the words in the verse are perfectly normal. In fact, all the natural language's orthography evolve over time. For example "cwēn", an Old English word, changed to "quen" in Middle English and later became "queen" [1, p. 142]. However, when it comes to Qur'an, the Muslim scholars decided to maintain the original spelling used in the second compilation of the Qur'an, which took place during Caliph 'Uthman's reign, a mere fifteen years after the Prophet's death [1, pp. 95-106]. So, even though this orthography differs from the present's, the text of the Qur'an 
and its orthography has remained unadulterated for the last fourteen centuries.

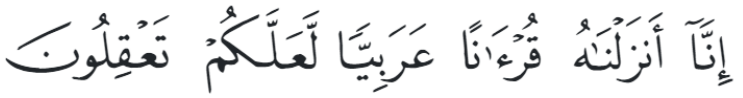

Fig. 1: Qur'anic verse showing the orthography used in the Holy Qur'an

While the Qur'an forms the bedrock of Islamic law, many legal details are derived not from the Qur'anic scripture, but rather from the utterances and actions attributed to Prophet Muhammad. These prophetic traditions, or hadiths, are narrations originating from the sayings and conduct of Prophet Muhammad. The detail of many of the Qur'anic knowledges can only be mined in the hadith literature. This is why Muslims believe the hadith complements the Qur'an. For instance, the detail about the practice of praying is only found in the hadith literature. Unlike Qur'an, the hadith corpus is huge and runs into hundreds of volumes. It has an even larger supporting work, e.g., commentaries, biographic material [2]. Qur'anic NLP researchers can enrich their Qur'anic NLP research by leveraging the complementary hadith literature and should be cognizant of the fact that ignoring the hadith corpus can lead to erroneous conclusions.

Along with all these mentioned challenges, one of the biggest challenges in working with the Qur'an is that it is a divine scripture, which demands extra precaution so that its semantics or information retrieved remains intact [7]. Current NLP efforts are focused in overcoming all these challenges using various techniques. Performing NLP tasks on a language with all these problems is not a straightforward task and requires technical as well as linguistic support.

Given the challenges and opportunities of the Qur'anic language, a group of scholars, wrote a paper titled "Understanding the Qur'an: a new Grand Challenge for Computer Science and Artificial Intelligence" [10]. The authors pointed out that "Understanding the Qur'an" can be considered as a grand AI challenge for various tasks such as reasoning, knowledge representation, and knowledge extraction based on Qur'anic text among other challenges have to be solved by leveraging the power of latest NLP techniques.

\section{Inclusion and Exclusion Criteria}

Papers have been selected on the basis of keywords revolving around Qur'anic NLP. The search criteria uses the NLP keywords combination of "Quran" or "Qur'an" with "NLP" or "Grammar" or "ontology" or "translation" or "search" or "classifier" or "ml" or "knowledge" or "topic" or "corpus" or "question" or "authentication" or "verification" or "crowdsource". The search has been performed on the Scopus and Google Scholar platforms. The papers included meet the following inclusion criteria: (1) articles related to Qur'anic NLP and techniques related to machine learning and deep learning for Qur'an, and (2) articles related to comparisons of different techniques for used for a particular Qur'anic domain.

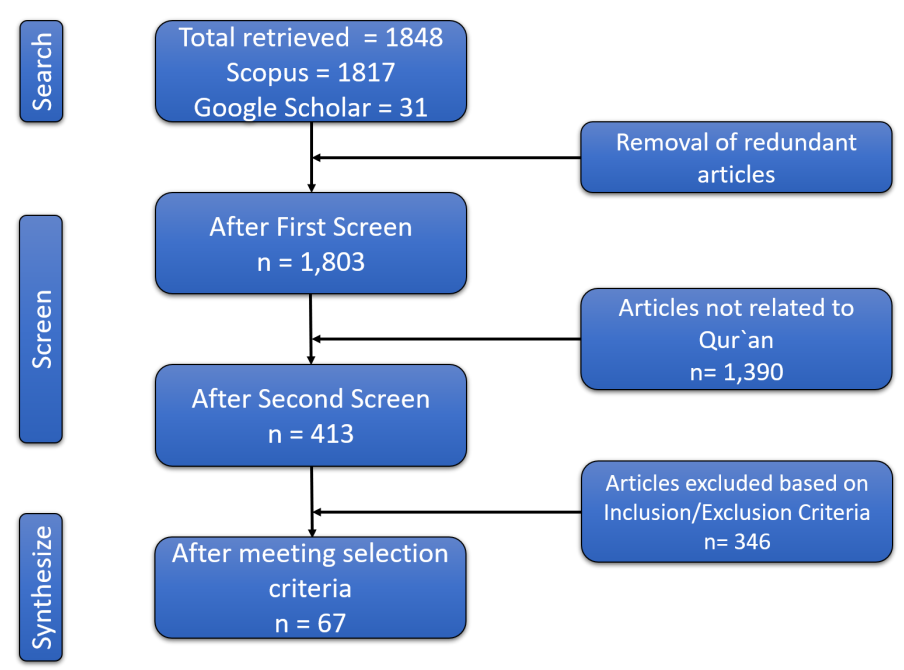

Fig. 2: Flowchart of paper selection

We excluded papers that are not related to Qur'anic NLP, and those not written in English language. In addition, we ignored incomplete works. Our search returned a total of 1,846 papers. After screening based on inclusion/exclusion criteria (Figure 2), eventually 65 papers were selected for our survey.

During selection the focus remained on the works which are closer to the Qur'an instead of Arabic only. Speech processing in general does not belong to NLP but for this paper it has been included to have a broad view of Qur'anic NLP. The papers surveyed can be categorized as shown in Figure 3.

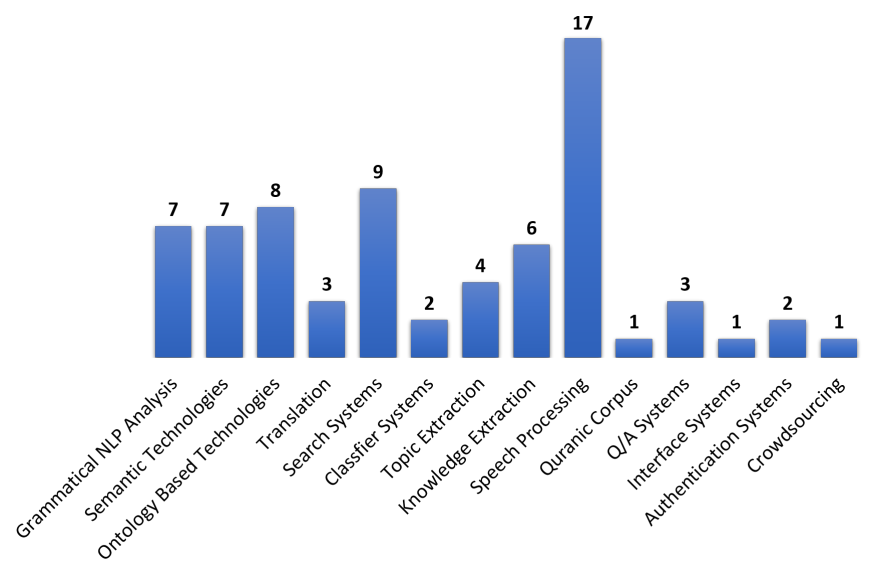

Fig. 3: Distribution of papers categorized according to their topic

The surveyed papers were published in different conferences and journals, though the majority were in journals. There is no specific journal or conference which holds dominance in publication of these papers. The publications have been done during the time period of years 2005 and 2021. Figure 4 below shows the percentage share of category of publication and the quantities op papers surveyed during different years.

The contribution of reviewed Qur'anic NLP research work is shared from across the globe. The heat map in Figure 5 shows the spread of research work across the globe for Qur'anic NLP 


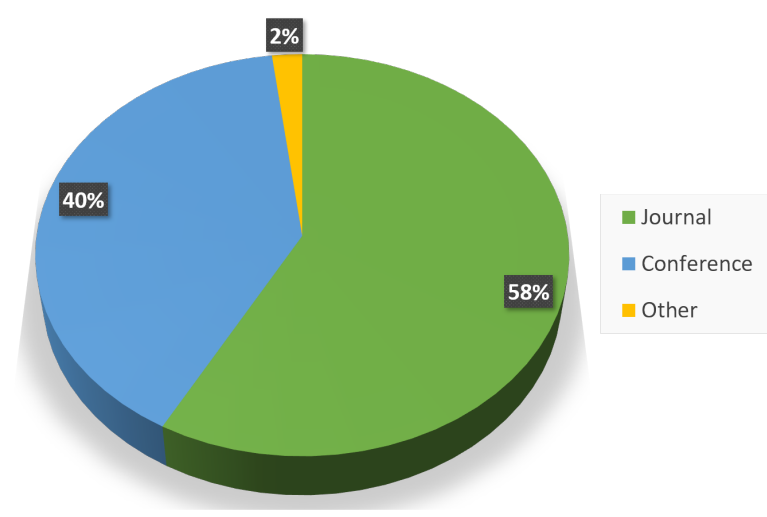

(a) Distribution of selected publications according to their types.

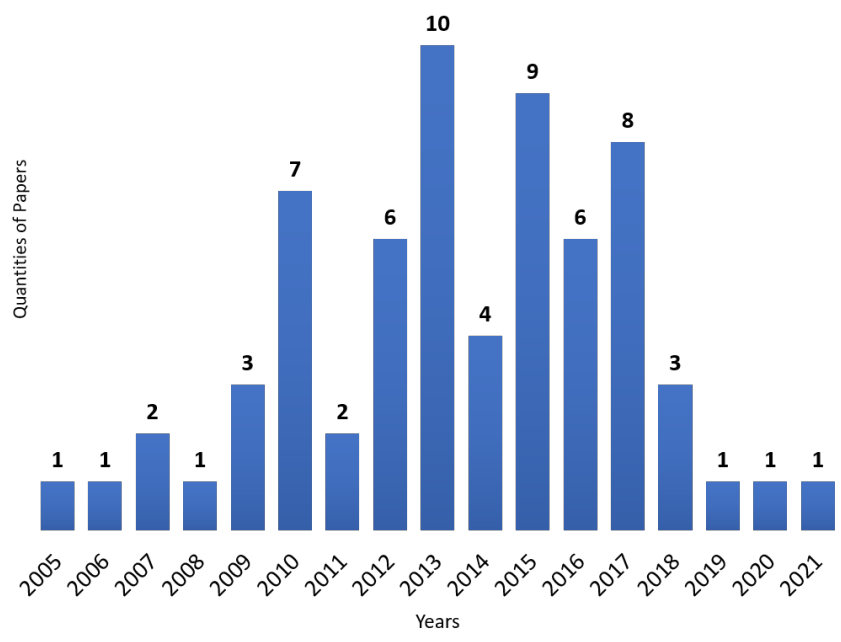

(b) Distribution of selected publications over years.

Fig. 4: Distribution of papers over publication type and years

reviewed in this paper.

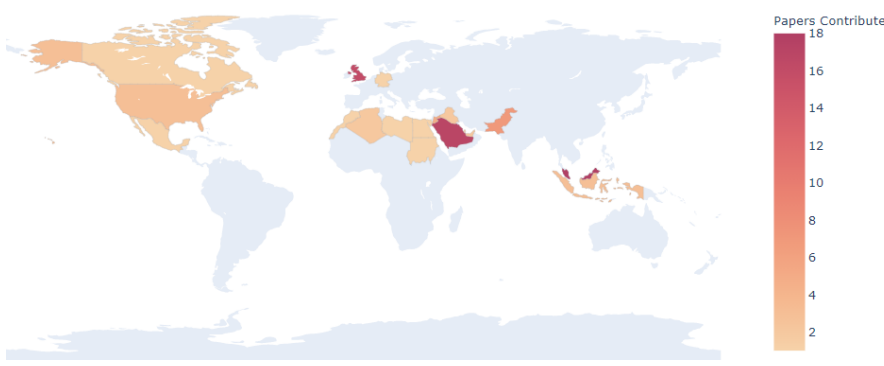

Fig. 5: Heatmap of Qur'anic NLP related research contributions reviewed in this paper

\section{Related Review Articles}

The work for Qur' anic NLP is not at limelight currently, but still a lot of efforts have been made over the past two decades to use the linguistic computation for Qur'an. Kammani and
Safeena [11] have reviewed various tools and techniques in this regard. Beside studying the efforts made in generic Arabic NLP, they have also reviewed the Qur'anic NLP. The review for Qur'anic NLP contributions is ranging from 1997 to 2011. They have discussed the development of Qur'anic corpus, annotations, morphological analysis, semantic searching, use of ontology for Qur'an, grammar tree bank and translation analysis. However, the review does not provide a variety of work for each category and just discusses one or two tools or techniques. There are other domains such as use of NLP and speech recognition for Qur'an recitation, question answering tools for Qur'an, knowledge extraction and topic modeling, which have not been highlighted.

Zaghouani [12] presented a survey of freely available corpora for the Arabic language with a limited number of papers related to the Qur'an and the Hadith. Atwell et al. [13] presented their own contribution towards Qur'anic NLP. The paper is focused on how how their work can be useful in the correct interpretation of Islam in the Western world. Qur'an-related NLP contributions described by them include open-source Qur'an corpus, conceptual search tool for Qur'an, grammatical analysis, classification of verses and chapter, ontological work and online tools. The paper does not cover much detail of each contribution.

Though not directly related to Qur'anic research, Azmi et al. [2] provides a comprehensive survey of NLP-based works on the complementary hadith literature. We note that the hadith literature, along with Qur'an, is one of the two canonical sources of Islamic knowledge.

Our work is focused on Qur'anic NLP instead of generalized Arabic NLP, as this would help in understanding the current status of Qur'anic NLP and will help researchers to contribute further with the help of already built applications. Techniques adopted for doing the Qur'anic NLP tasks have been discussed. The paper also covers the tools that have been used in various Qur'anic NLP tasks. The comparison of this paper with previous such reviews is shown in Table II

TABLE II: Comparison of our work with others

\begin{tabular}{lccc}
\hline $\begin{array}{l}\text { Qur'an NLP Work } \\
\text { Reviewed }\end{array}$ & {$[\mathbf{1 1}]$} & {$[\mathbf{1 3}]$} & This paper \\
\hline Grammatical work & $\checkmark$ & $\checkmark$ & $\checkmark$ \\
Semantic work & $\checkmark$ & $\times$ & $\checkmark$ \\
Ontology & $\checkmark$ & $\checkmark$ & $\checkmark$ \\
Translation & $\times$ & $\times$ & $\checkmark$ \\
Search system & $\checkmark$ & $\checkmark$ & $\checkmark$ \\
Classification & $\times$ & $\checkmark$ & $\checkmark$ \\
Topic Extraction & $\times$ & $\times$ & $\checkmark$ \\
Knowledge Extraction & $\times$ & $\times$ & $\checkmark$ \\
Speech Processing & $\times$ & $\times$ & $\checkmark$ \\
Qur'anic Corpus & $\checkmark$ & $\checkmark$ & $\checkmark$ \\
Q/A Systems & $\times$ & $\times$ & $\checkmark$ \\
Interface Systems & $\times$ & $\times$ & $\checkmark$ \\
Qur'an Authenticity & $\times$ & $\times$ & $\checkmark$ \\
Crowd sourcing & $\times$ & $2004-2011$ & $2005-2021$ \\
Review Timeline & $1997-2011$ & Qur'an & Qur'an \\
Focus & Generic \& Qur'an & & \\
\hline
\end{tabular}




\section{E. Contributions of this paper}

This paper aims to review the Qur'anic NLP research work performed including the techniques and tools used in them. Surveyed work is related to the applications and systems developed for Qur'an based on NLP. The paper will highlight various challenges that have been overcome related to Qur'anic NLP, major contributions and the areas that still require attention. Main purpose of writing this paper is to consolidate the current status of Qur'anic NLP works and help the researchers to work ahead of that. The papers have been searched on the basis of following survey objective:

1) To study and survey the current research work related to Qur'anic NLP.

2) To study the techniques, tools and resources being used for Qur'anic NLP.

3) To find the limitations and pitfalls of Qur'anic NLP works.

\section{F. Organization of this paper}

The rest of the paper is organized in the following way. Qur'anic NLP techniques are described in Section II. A broad survey of Qur'anic NLP related works is provided in Section III. A discussion on various tools and resources available for Qur'anic NLP research follows in Section IV. The various caveats of doing AI-based NLP research for Qur'anic research and potential pitfalls are discussed in Section V. Open issues and future research directions are identified in Section VI. Finally the paper is concluded in Section VII.

\section{QUR'ANIC NLP TECHNIQUES}

In NLP, different techniques are involved in order to gain some useful output from the input data. Some techniques are basic and are used in almost all applications while others are task specific. Figure 6 shows the overview of techniques involved in the Qur'anic NLP tasks and they are further explained in each subsection. In the remainder of this section, these are discussed in more detail.

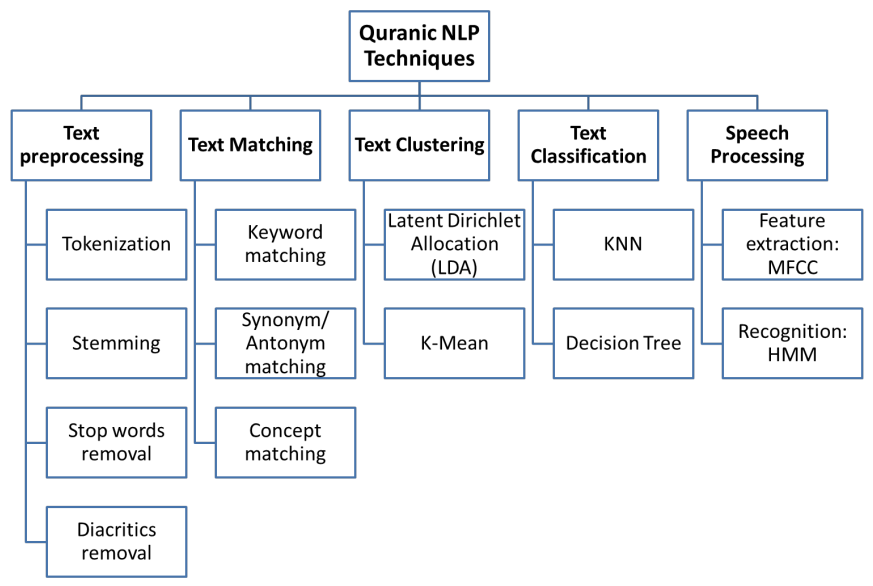

Fig. 6: Techniques used for Qur'an NLP tasks

\section{A. Text Preprocessing}

Text preprocessing is one of the basic steps that is used in almost all the textual NLP tasks. Preprocessing involved in the NLP tasks of the Qur'an mostly begins with the tokenization. The given corpus from the Qur'an may consist of multiple chapters, divisions or verses. One verse is like a sentence. These verses are tokenized into words. In Arabic, a particular word may consist of multiple units, so depending on the requirement, these words can be further segmented into morphological segments. In certain applications, such as question answering platforms or search systems, Qur'anic words are stemmed to their roots. Like English, Arabic also contains many stop words. Stop words removal is essential in tasks like topic modelling of the Qur'an and finding similar verses. For the help of Non-Arab Muslims, diacritic marks are present on the words of Qur'an. These marks help as a guide for the reciters in order to avoid mistakes and confusions. However, these marks can increase the complexity while processing the text through machine. In almost all the tasks, the diacritics are removed from the words in the preprocessing stage.

\section{B. Text matching}

Text matching technique has been widely used in search systems developed for Qur'an. Text matching can be used in multiple forms. In some applications, exact words of user query are matched with that of verses. In other applications, the query words and the words of verses may be converted to their roots so that they could be matched to any form they have been used in. This technique increases the search window. Text matching in advanced form can be used in semantic tasks related to the Qur'an. Here, the search window size can be further enhanced using synonyms or antonyms of a particular word. Retrieving concepts from any text cannot be done by simple word matching. Conceptual results can be retrieved using ontology where matching of words is performed at different hierarchical levels. Although text matching may seem to be a very basic technique, but if used properly, it can help in achieving great results.

\section{Clustering}

Clustering is an unsupervised machine learning technique which is used to cluster similar kinds of data. In unsupervised learning, labels are not available. For the Qur'an, similar kind of verses are grouped together for the categorization and knowledge extraction tasks. There are various algorithms for clustering but for topic modelling in particular Latent Dirichlet Allocation (LDA) is the most widely used. LDA calculates the probability of words distributed over a topic and then allots multiple topics to each document [14]. Topics discussed in Qur'an can also be listed, by using clustering technique on the Qur'anic verses. Besides, LDA, K-means algorithm is also applied for the categorization of the Qur'an verses. K-means is a clustering algorithm in which given verses are clustered into known number of groups, depending on the distance of words in verses from centroids of each group. K-means algorithm is simpler in implementation as compared to LDA. 


\section{Classification}

Contrary to clustering, classification is a supervised machine learning technique which is also used for the topic modelling of the Qur'an and knowledge extraction. In classification, data is already labelled. K-Nearest Neighbours (KNN) is widely used in classification tasks. In KNN, there is a set of verses which already labelled with particular topics. The verses under test are then allocated a topic by finding their similarity with labelled verses using a distance formula. Decision tree is the other classification model. The model is used in the application of knowledge extraction and question answering for Qur'an [15]. In decision tree algorithm, training data is classified based on the input features. The testing data is then allotted labels based on the rules developed by decision tree during training.

\section{E. Speech processing}

Speech processing has been used in multiple tasks related to the correct recitation of the Qur'an, which have been discussed in Qur'anic NLP works section. Speech processing helps in conveying the natural sense of spoken languages. For Qur'an, it is essential to recite with certain rules. In speech recognition Mel-Frequency Cepstral Coefficient (MFCC) is used for feature extraction of the speech. MFCC is designed to replicate the human auditory system artificially [16]. The feature extraction using MFCC is shown in Figure 7.

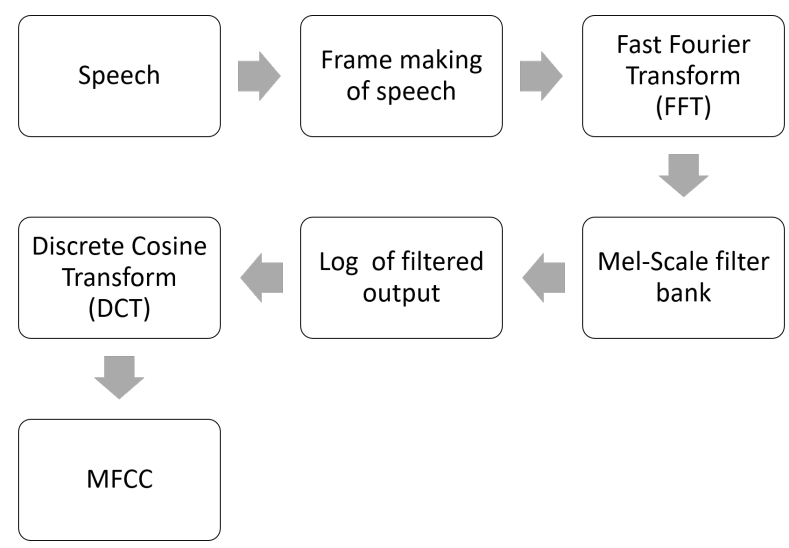

Fig. 7: Block diagram of MFCC feature extraction from speech

Hidden Markov Model (HMM) is used for training and testing of speech data. HMM based recognizer takes feature vectors created by MFCC as input and then uses Bayesian probability to recognize words from phonemes trained over multiple pronunciations of each word [17]. HMM is a state machine where each state in a particular time is associated with a specific phoneme and a particular word is obtained by observing these sequence of phonemes [18].

\section{QUR'ANIC NLP WORKS}

Quranic NLP tasks are reveiwed in this section. Figure 8 shows the categorization of tasks.
TABLE III: Comparison of treebanks

\begin{tabular}{lccc}
\hline Treebank & Dependency & Feature & Traditional \\
\hline Penn & No & Yes & No \\
Prague & Yes & Yes & No \\
Columbia & Yes & No & Yes \\
Qur'an & Yes (hybrid) & Yes & Yes \\
\hline
\end{tabular}

\section{A. Grammatical NLP Analysis}

Arabic grammar can be understood in terms of morphology and syntactical analysis. The Syntactic analysis along with morphology in NLP have to cater all the rules such as the use of correct form of word, placement of word in the correct place within a sentence and relating nouns verbs and particles properly. For this purpose, various Arabic tree banks have been developed. To study the Qur'anic grammar, Dukes et al. [19] have developed Qur'anic Arabic Dependency Treebank (QADT). Treebank is basically a huge dictionary of manually verified syntactic analyses of sentences. QADT is part of Qur'anic Arabic Corpus (QAC) [20]. Morphological analysis for all the 77,430 words of the Qur'an has been completed with the help of a collaborative approach. However, syntactic relation analysis is yet in progress and has covered 11,000 words so far. Table III shows the comparison of other general Arabic treebanks with Qur'an dedicated QADT:

Morphological annotation involves segmentation of each word into morphemes and assigning part of speech to each of them. The morphological annotation adopted in QADT for the Qur'an is described by Dukes et al. [21]. A three staged systematic method is adopted for the morphological tagging which includes automatic tagging, two-pass manual verification and online collaborative annotation. Automatic tagging is done by using existing Buckwalter Arabic Morphological Analyzer (BAMA) aided by a custom tool. In manual tagging, one of the annotators verifies the automatic tags and the second one reviews the text after her/him. Finally, the accuracy is further improved by online collaborative platform. Automatic algorithm provides analysis for $87 \%$ words of the Qur'an; the remaining $13 \%$ were not catered because of low vocabulary of BAMA. For $87 \%$ words, automatic annotation provided $77 \%$ accuracy and $83 \%$ recall.

Traditional Arabic has complex functional inflection. For example, a noun can be written in different ways depending on its position against its verb. Also a single word may consist of multiple morphological units syntactically related to each other. Dukes et al. [22] have explained the process of syntactic annotation and key guidelines for annotations of Qur'anic verses based on QADT. Guidelines are important because, Qur'an is a divine scripture. An iterative approach is adopted to annotate the corpus similar to that of morphological annotation. Initially rule based dependency parser having F-measure of $78 \%$ is used. Next step is to perform manual check of annotation for corrections using existing traditional grammar rules and annotation guidelines. Interested volunteers regularly participate in online annotation. Annotation guidelines are added and updated on the basis of this online collaborative work. There are multiple guidelines such as sentence structure 


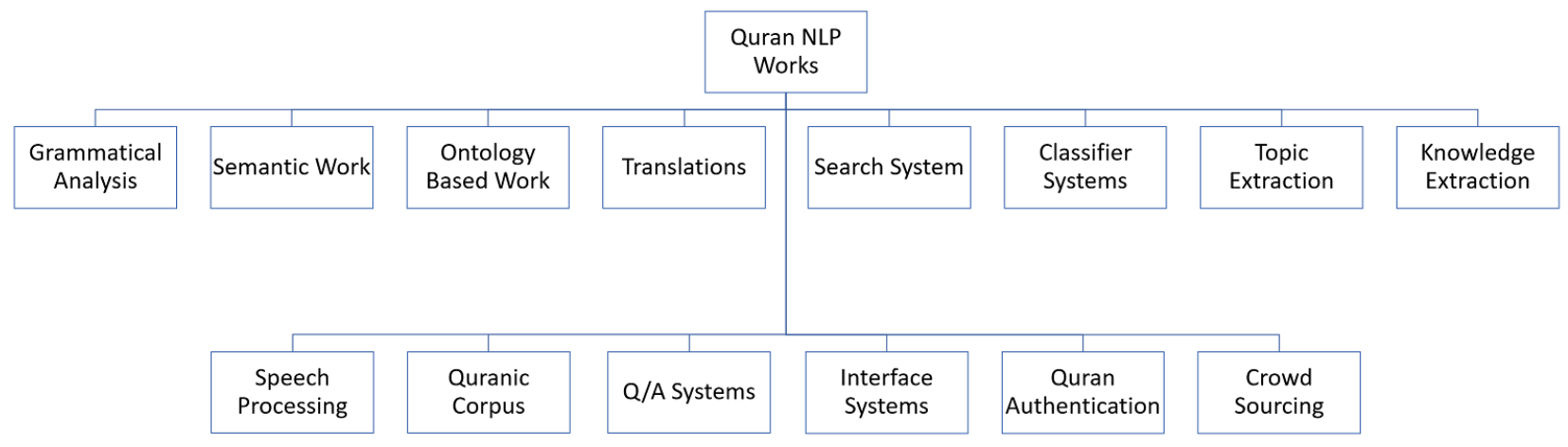

Fig. 8: Categorization of NLP works

based on subject, verb and object, use of empty and hidden nodes for reconstruction and prepositional phrase attachments. The supervisors have a role to veto any decision as they are more knowledgeable and they see if the annotation done is aligned with Qur'an or not [23].

Visualization tool can be a great replacement of traditional methods and help Arabic linguists and Qur'anic students understand traditional Arabic grammar more easily. Dukes et al. [24] report the capability of graphical dependency graphs in QADT to present the syntactical relationship of words with a sentence. Each word may consist of multiple segments. To perform this computational analysis, graphs have been developed which connect different words with in a sentence or with words of other sentences. This technique allows to understand relation of different segments, words and phrases in Qur'an. Detailed morphological visual analysis of verses is also provided. Grammatical analysis of each morpheme is shown with different color coding. POS tagging and morphological annotations provide high accuracy under random sample testing. Figure 9 shows the visual representations for morphology and syntactic analysis.

Bentrcia et al. [25] have studied the conjunctive phrases in Qur' an based on 'AND' conjunction and have shared interesting findings. There are three different cases that are recorded with 'AND' conjunctive phrase which are; words occurring in specific order only once, words occurring in specific order multiple times and words occurring in different order one time or multiple times. The corpus used for the project is the QAC and combination of statistical and grammatical method have been adopted to mine the required conjunctive phrases. There are many cases in which words are combined by 'AND' but in the study, ten patterns which consist of only nouns, pronouns and adjectives combined by 'AND', are considered. The results and analysis reveal that words occurring in some specific order are based on some logic. For example, 'Isaak' is always mentioned before 'Jacob' because the former was the father of the latter and 'East' is always mentioned before 'West' because in time frame east comes before west. The order of the words in conjunctive phrase hold significance based on the context of the verse. Pointwise mutual information is also recorded

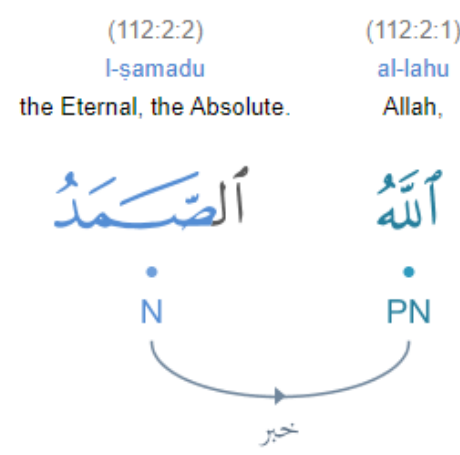

(a) Dependency graph for verse showing syntactical structure $(112: 2)$

(23:41:4)

faja'alnāhum and We made them

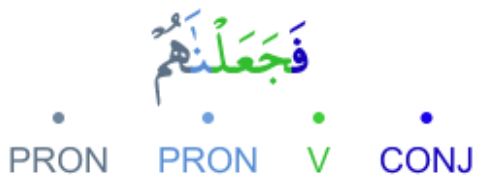

(b) Morphological segmentation for word (23:41:4).

Fig. 9: Visualization of Dependency graph and Morphological analysis of Qur'an [20]

for the words joint by 'AND' word which show that words occurring multiple times together have higher association.

ELAffendi et al. [26] have recently used a neural network based approach to predict the morphological patterns and POS tags for Arabic. Galois Power-of-Two (GPOW2) calculates the real time embeddings for character, word and sentence in parallel. Each word is represented as a polynomials of power of two. The QAC is used as a dataset which holds rich morphological and syntactic annotations. The model works by computing the contextual embeddings of a word at input stage. GPOW2 representation of these embeddings are fed to the 
neural network which then tries to predict the tag for the target word. The test accuracy for POS tags prediction is $98.8 \%$ that is quite great considering the complexity of the Arabic morphology.

Table IV summarizes this section.

\section{B. Semantic Technologies}

Sherif et al. [27] have developed a database which contains semantic dataset in 43 languages for the Qur'an. Tanzil is a web-based resource of multi-language Qur'anic translations for the dataset and QAC provided the morphological data for each word. The data has been presented in the Resource Description Framework (RDF). Out of 43 languages, only three translations along with original Arabic dataset comply RDF and NLP Interchange Format (NIF). NIF achieves interoperatability between NLP tools, language resources and annotations. RDF consists of four main classes of Chapter, verse, word and lexical term which give a hierarchical structure to the whole dataset. The dataset has been linked with multiple online platforms for use. It helps in data retrieval from the Qur'an in multi-languages. Using the SPARQL, the user can also perform morphological queries on data. Other useful applications include information aggregation and finding multiple occurrences of a particular text in the database.

AI-Khalifa et al. [28] have proposed a web based framework under the title "SemQ" which performs semantic opposition analysis on Qur' an using NLP and semantic web technologies. In semantic opposition analysis, opposites of a word or phrase are searched based on their characteristics. SemQ takes input in the form of verse and in return it provides an output which is a list of words that are semantically opposite to each other. Ontology based on Greek New Testament and SemQ Tool work together under the framework. After NLP preprocessing, the algorithm starts working by checking if the two words under consideration belong to same category. If only one property of words differs, they are declared absolute semantic opposite; if more than one properties differ then the scale of opposition is calculated. The SemQ team aims to build prototype in future for complete Qur'an and compare the results with traditional approaches.

Hammad et al. [29] have tried to address the problem associated to keyword search system for Qur'an. Many times, intended results are not achieved as keyword search does not cater for conceptual or semantic analysis for the query. They have presented a semantic and lexical based search system to overcome the issue. Database with the name of Qur'anic English WordNet (QEWN) is developed. In this database, all the words in English translation of the Qur'an are populated along with their semantic information. Vocabulary of Qur'anic Search (VQC) stores various concepts included in Qur'an. Concepts of sense and Synset is utilized in QEWN. Sense means a particular meaning of a given word and Synset is the collection of synonyms of that word in a particular sense. Upon search of a particular word, all the semantically related verses are returned. Even if the search word does not exist in translation, the tool searches for the related concepts using synonyms. The tool also performs a unique search of Islamic concepts such as the "pillars of Islam" which will return all the verses related to five pillars of Islam. This semantically rich tool has been able to achieve $88 \%$ recall for the words which are directly present in translation and 59\% for the words that do not appear directly but are searched using different synonyms in a particular sense.

Shoaib et al. [30] have also tried to resolve the problem which is associated with keyword-based search in which either exactly required verses are not retrieved or irrelevant results are returned They have also utilized WordNet database to perform semantic search on Qur'an. Topic search is a two-step process. In the first step, desired meaning of the query word is interpreted while other senses are ruled out. Afterwords, topic is searched using that word or synonyms of that word. These synonyms are categorized as exact synonym, close or strong synonym and weak synonym. The systematic algorithm returns verses in the priority list. The model has been implemented on English translation of Surah Al-Baqarah (Chapter 2) using SQL and VB.Net. The model is also able to achieve great results by retrieving $80 \%$ more relevant results as compared to other models. It is also able to minimize the retrieval of irrelevant results.

Alqahtani et al. [31] have reviewed various techniques to perform semantic search on Qur'an and have proposed their own framework. Search techniques fall into two types. One is semantic search in which the concept-based search applied and the other one is keyword-based search in which direct search is performed using some particular word without catering for concept. The Qur'anic semantic search methods can be categorized as ontological search (concept based), synonym-set search (based on synonyms of query word) and cross language information retrieval (CLIR). In the keyword search, if any of the query word is matched with any word of the verse, the verse is retrieved. Preprocessing on words are performed with the help of morphological analysis. Keyword based search also utilizes chatbot technique in which some of important word are chosen from whole query and search is performed for those words only. However, keyword-based search frameworks are deficient of providing relevant results and many times provide irrelevant verses. On the other hand semantic search does not cover all the concepts of Qur'an. Keeping these limitations of both techniques in view, a new semantic framework is proposed called Qur'anic Semantic Search Tool (QSST). When a query is entered, it is preprocessed and results are retrieved separately for both semantic and keyword search. Redundant verses are eliminated and finally verses with highest ranking as scored by QSST are returned to the user.

Yunus et al. [32] have performed semantic search using Cross Language Information Retrieval (CLIR) and showed the results visually using a space tree model. The system supports search in Malay, English or Arabic. Each word in query is stemmed to its basic form along with its synonyms. This increases the search range and can help in retrieval of more results. Finally the results are retrieved and verses IDs are displayed in the form of a tree structure where system is further integrated to speech query [33].

A summary of this section is provided in Table V. 
TABLE IV: Qur'an Grammatical NLP Works Table

\begin{tabular}{|c|c|c|c|}
\hline Sr. & Research & Issue Addressed & Technique Applied or Contribution \\
\hline 1 & Dukes and Buckwalter [19] & Lack of manually verified Qur'anic corpus and treebank & Development of QADT and Qur'anic Corpus \\
\hline 2 & Dukes and Habash [21] & Lack of morphological annotation of the Qur'an & $\begin{array}{l}\text { Systematic, collaborative approach for morphological } \\
\text { annotation of the Qur'an }\end{array}$ \\
\hline 3 & Dukes et al. [22] & Lack of syntactic annotation of the Qur'an & $\begin{array}{l}\text { Systematic, guideline based and collaborative approach } \\
\text { for syntactic annotation of Qur'an }\end{array}$ \\
\hline 4 & Dukes et al. [23] & lack of supervision of syntactic work for the Qur'an & Inclusion of Supervisors to monitor the annotation \\
\hline 5 & Dukes et al. [24] & $\begin{array}{l}\text { Lack of user friendly interface to understand Qur'an } \\
\text { grammar }\end{array}$ & $\begin{array}{l}\text { Dependency graph for verse structure and Color coding } \\
\text { for morphology }\end{array}$ \\
\hline 6 & Bentrcia et al. [25] & $\begin{array}{l}\text { Understanding logic in placement of words around } \\
\text { conjunctions in Qur'an }\end{array}$ & $\begin{array}{l}\text { Study of placement of nouns, pronouns and adjectives } \\
\text { occurring with 'AND' }\end{array}$ \\
\hline 7 & ELAffendi et al. [26] & Prediction of POS for Qur'an & $\begin{array}{l}\text { Use of GPOW2 for context based POS prediction using } \\
\text { neural network }\end{array}$ \\
\hline
\end{tabular}

TABLE V: Semantic Work for Qur'an

\begin{tabular}{|c|c|c|c|}
\hline Sr. & Research & Issue Addressed & Technique Applied or Contribution \\
\hline 1 & Sherif and Ngonga Ngomo [27] & Semantics of Qur'anic Words & $\begin{array}{l}\text { Development of the Qur'an semantic database and } \\
\text { integration with online platforms }\end{array}$ \\
\hline 2 & Al-Khalifa et al. [28] & Semantic opposition analysis of the Qur'an & $\begin{array}{l}\text { Development of "SemQ" to perform semantic opposi- } \\
\text { tion analysis of Qur'anic verses }\end{array}$ \\
\hline 3 & Afzal and Mukhtar [29] & Lack of semantics in keyword based search for Qur'an & $\begin{array}{l}\text { Development of QWEN database and VQC search } \\
\text { system for Qur'an based on synonyms of words }\end{array}$ \\
\hline 4 & Shoaib et al. [30] & Lack of semantics in keyword based search for Qur'an & $\begin{array}{l}\text { Development of framework to retrieve English verses } \\
\text { of Al-Baqarah chapter, based on various degrees of } \\
\text { synonyms. Accuracy up to } 80 \%\end{array}$ \\
\hline 5 & Alqahtani and Atwell [31] & $\begin{array}{l}\text { Study of shortcomings of existing semantic and key- } \\
\text { word based Qur'an search systems }\end{array}$ & $\begin{array}{l}\text { Development of QSST to perform semantic + keyword } \\
\text { based search }\end{array}$ \\
\hline 6 & Yunus et al. [32] & Semantic search of the Qur'an & Development of CLIR system for Qur'an \\
\hline 7 & Yunus et al. [33] & Lack of user friendly semantic search system & $\begin{array}{l}\text { User friendly tree structure based output along with } \\
\text { speech query }\end{array}$ \\
\hline
\end{tabular}

\section{Ontology Based Technologies}

Ontology is a hierarchical dictionary of concepts. Since machines cannot understand the concepts like humans, so we need to provide them an easy way to understand the concepts. Ontology is also used for Qur'an in order to explain the various concepts easily. Maha et al. [34] have made an effort to contribute towards the Arabic computational lexicon using the approach of ontology. Lexicon can be defined as the vocabulary of a language where each word is set accompanied with a few other words which define its properties. 59 nouns related to the semantic field of "Time" are chosen in the project from the Qur'an. Component analysis of the words belonging to the same semantic field and having similar context, help in differentiating them from one another. The team adopted Unified Process for Ontology (UPON) which is a unified software development process driven methodology for the development of ontology. Words were classified in a hierarchy having general concepts leading down to more specific ones. There were 18 conceptual classes defined for the time in which eleven were specific to time field. It can provide synonyms as well as antonyms based on the component analysis. The model was tested for 31 other time words and also words from human semantic field, given in Qur'an.

Rizwan et al. [35] have pointed out the limitations of already existing Qur'anic ontologies and also developed a new ontology for the 30th Juz (Division) of the Qur'an in order to address those limitations. The list of limitations, highlighted by the team while studying previously developed ontologies is described next.

1) Ontology developed for just one topic, for example Salah.

2) Limitation of ontology to answer all the questions related to a topic.

3) Limited concepts inclusion in ontology.

4) Linking different concepts related to verses but not catering for their contextual meanings.

5) Methodologies adopted to develop the ontologies do not follow some systematic approach.

The ontology developed by Rizwan et al. [35] is sourced from authentic Qur' anic corpus. Ontology is capable of providing contextual meaning of verses based on Hadith and Tafsir. Ontology has been developed by merging different ontology methods. It provides details of surah (chapter) included in the $J u z$ (division). Ontology is developed for English and Malay translation. Two ontology development methods have been adopted in the project, which are Gruninger and Fox's methodology and METHONTOLOGY methodology [36]. The Ontology developed, was able to provide correct answer to the queries. The framework can be adopted in many semantic and online Qur'anic applications owing to its flexible design.

Hikmat et al. [37] have proposed ontological approach to perform semantic search for the Qur'an. Ontology for animal 
domain has been developed in order to avoid any conflict regarding divine concepts. Developing animal ontology for 167 animals, described in Qur'an, is also not an easy task as the context has to be specific as per Qur'an. The team has selected the English translation. To improve the results further, team developed separate ontology on scientific facts or other related information of animals and then linked it to the original Ontology of Qur'an. In this way the actual concept of the Qur'an are not mixed with other data. To perform the Query, SPARQL query language is used. The framework provides great results. It has been proposed to develop Qur'anic WordNet that will further help to perform better semantic search on Qur'an as the currently available WordNets are generic and do not suffice the requirement of specificity of Qur'anic concepts.To enhance the framework further for whole Qur'an and other Islamic literature, team has proposed a simple workflow. Query will be passed through Qur'anic WordNet and ontological concepts will be linked to the words. Finally, the answer will be retrieved.

Azman et al. [38] have also used ontological method to represent the Qur'an under thematic structure. In the Qur'an, the same concept is described in more than one verses and in different surah. The team has worked to bring all the verses belonging to one theme under one umbrella. To perform the thematic classification, team has selected Syammil AlQur'an Miracle and only two themes are selected which are Akhlaq (Manners) and Iman (Faith). Classes are defined where each class has a subclass. For example, Iman is the main theme and belief in Allah is its sub-theme. Each sub-theme can have different divisions, chapters and verses. Themes are developed from the reference book and also by interviewing the expert scholars. The ontology is developed in Malay language. and validated by the seven experts of the Qur'an. The ontology based thematic applications can be very helpful in understanding concepts of the Qur'an in better way.

Ta'a et al. [39] also developed theme based ontology named as Al-Quran to perform the semantic queries. Ontology is developed using Protégé-OWL. The ontology does not cover the whole Qur'an, but only three main classes which are; Allah, Angels and Unseen. For these classes, sub themes are developed with the help of Islamic scholars to keep the original meaning intact. The Qur'anic data is saved in a database on which SQL queries can be performed to retrieve results. Graphical User Interface of ontology allows user to select the main theme and two subthemes. This helps the user to search the intended query more easily.

Scmmal et al. [40] have reviewed the already built Qur'an ontologies along with Qur'anic Search applications and tools. Applying semantic search on Qur'an is not an easy task. One verse may contain multiple themes or single theme may exist of multiple verses. Different search tools developed try to address different challenges. Still there are few limitations in the proposed semantic search tools, which are described next.

1) Unavailability of solution if the terms of query do not match the concept of ontology.

2) Limited vocabulary of Arabic WordNet.

3) Incomplete link development of verses with their concepts.
Similarly, the authors have performed research on the available Qur'anic ontologies. Most of these ontologies revolve around verses' similarity and relationship, animals or some specific Qur'an topic. The team has proposed a new search tool called Arabic Qur'anic Semantic Search Tool (AQSST) by combining four different ontologies. The database consists of original Qur'anic text along with eight different English translations. It also contains Tafsir which is explanation of concepts of verses. NLA performs parsing and semantic tagging to the query words and then concepts based search is performed using SRM. If the search is unsuccessful, then KSM is applied. Finally, suitable results are retrieved after on the basis of score provided by SR. The tool has tried to overcome the limitations and challenges which are highlighted in the start.

Ahmed et al. [41] have investigated the practical applicability of performing semantic search for abstract concepts of the Qur'an based on different ontologies merged together. There are different methods to merge the ontologies such as similarity measure, heuristic method and methods involving semantic and syntax. The three ontology methods applied in this ongoing project are:

1) Extract abstract concepts with the help of domain expert.

2) Semi-automatic extraction of concepts from the original text source.

3) Reuse the existing partial ontologies.

Initially, three different ontologies are merged together. These ontologies are combined on the basis of Jaccard similarity which measures similarity between sets of data. The other method adopted is using a PROMPT tool which takes two ontologies as input and then returns one merged ontology. Both methods provide satisfactory results. First method gives correct resolution of results up to $82 \%$ while second provides $85 \%$. The approach in future is to complete all the three methods mentioned at the beginning and create a single ontology which will be sufficient to perform the semantic search on Qur'an.

Alqahtani et al. [42] have discussed the advantages of aligning and merging different ontologies. Only a few among various ontologies for Qur'an discuss all the concepts. Three most common ontologies with their features are discussed in Table VI.

TABLE VI: Different ontologies and their features

\begin{tabular}{ll}
\hline Ontology & Feature \\
\hline Qur'anic Topics & $\begin{array}{l}1100 \text { concepts linked to all verses. It is based } \\
\text { on Scholarly book Mushaf Al Tajweed }\end{array}$ \\
Arabic Qur'an Corpus & $\begin{array}{l}300 \text { concepts and 350 relations from the } \\
\text { Qur'an. It is based on "Tafsir Ibn Kathir" } \\
\text { Qur'an }\end{array}$ \\
& $\begin{array}{l}1050 \text { concepts and 2700+ relations to Qur'anic } \\
\text { verses }\end{array}$ \\
\hline
\end{tabular}

In order to merge these ontologies first of all they need to be normalized so that all of them have the same format. After that, same concepts are aligned on the basis of string matching and semantic matching. There is also a structural approach in which entities are matched on the basis of ontology graph. The advantage of merging different ontologies into one is that 
more knowledge is gathered at one place and it can enhance the search results of topics for Qur'an.

The section is summarized in Table VII.

\section{Translations and Qur'anic NLP}

Kammani et al. [43] has discussed the challenges related to Qur'anic translation and then proposed a conceptual method to overcome them. Very little effort has been made to translate the Qur' an on knowledge basis. Many researchers have pointed various challenges regarding translation. Morphological and lexical challenges are most common among all challenges. Many native Arabic speakers feel challenged while identifying exact meanings of some words or sentences from the Qur'an. However, a knowledge based translation developed with the help of new technologies can provide exact meaning for such words or sentences. In the current era, a lot of effort is being put in Qur'anic Arabic and modern Arabic computation research work. Three research gaps were found in these work. First one is ignorance to the context and chronological order of Qur'an. Second one is the inability to answer the complex questions. Third one is that existing work do not offer complete search and analysis. To address these gaps a translation system is proposed in which Qur'an and authentic Hadith will be the knowledge base and at the top of it will be an expert engine which will be responsible for the content, context and chronology of the verses.

Putra et al. [44] have reviewed concepts related to text mining, searching and question answer (SQA) application and Indonesian Translation (ITQ). The review is conducted in three phases which are planning, conducting and reporting. Many people search for solution of their problems from the Qur'an in the Indonesian language. SQA is a search engine developed on the basis of ITQ to provide information to people in Indonesian language. Discovering Source Answer (DSA) is the component of SQA whose function is to perform sentence detection, POS tagging and text processing etc. The other component interprets the query and returns the results. The relevant passages are returned for the query and then ranked before finally returning results to the user. There are few issues associated with text mining related to ITQ. One of the biggest problems is the ambiguity of the word meaning, as one word may have many meanings, so the correct results may not be returned for particular query.

Hanum et al. [45] have developed a parser system for the Malay translation of the Qur'an. The system checks the correctness of the grammar as per standard Malay Grammar rules, using Earley's algorithm. The Malay translation of the Qur'an, selected for the project, has 40,290 words. Each sentence is parsed by initially splitting each sentence or verse into multiple sentences or parts. For each word in the sentence, grammatical rule is predicted. At the end, a parse tree showing all the rules is developed for all the sentences. The sentence structure of the Malay translation is verified against Standard grammar rules. The standard Malay grammar is evaluated by performing 42 experiments. It was found that many sentences did not follow the standard Malay grammar rules. New set of rules consist of 115 rules and the original standard Malay grammar has 94 rules.

\section{E. Search Systems and Qur'anic NLP}

Hammo et al. [46] designed a search engine using query expansion techniques and tested if the search results can be improved or not. Each verse is tokenized and the words are then stored in three different indexes which are VowelizedWord Index, Non-vowelized-Word Index and Root Index in RDBMS. The Vowelized Index holds all the distinct words of the Qur'an without any preprocessing. Hence the diacritical marks are present on them. The non-vowelized index is formed by removing diacritics from the words and finally the root index is used to store the root words which are formed by stemming all the words to their base. There is also a Thesaurus in the database which holds the synonyms of Qur'anic words. Three experiments are performed. In the first experiment, the query word was used for search and it was found that results were not good as the input query may or may not match exactly with the desired word from the Qur'an. In the second experiment, stemming of the query word was done and then it was searched in root index. Once the word was found in the table, the query expansion was done by finding the related word in vowelized and non-vowelized tables. The experiment showed great improvement in results. In the last experiment, query expansion was done using Thesaurus, which searched the verses for query word based on synonym approach. This also showed great results. Overall, it was concluded that, query expansion is a great way to perform search on Qur'an.

Al-Gharaibeh et al. [47] have studied the use of formal methods for Qur'anic NLP-based search engine. Formal methods are techniques that are used to describe and specify a software tool. These specifications are expressed using Z-notation. The approach first describes the schema in an informal way, then defines the syntax of operations to be performed for searching and finally define axioms which will help in performing operations. There are three types of search techniques included, which are text-based, stem-based and synonym-based schemas. Schemas are developed for each approach by performing some preprocessing such as stop word and diacritics on the Qur'anic text. In first approach, exact query word is matched with the words of the verses. In the stem-based approach, word stemming is performed for query word and words of the verse. In the synonym-based approach, synonyms are used to perform the search. The search engine is developed using Z-notation which has its own syntax. Z/EVES tool is used to develop the schemas and then evaluate the performance of the system developed.

Yunus et al. [32] have designed a Qur'anic search framework that performs Cross Language Information Retrieval (CLIR) with the aid of semantic and stemming analysis on query. The system takes a query from the user. It is then converted into target language equivalent query. The system can answer the results in one of the three languages from Arabic, Malay or English. After the translation, each word of the query is passed through a semantic analysis in which synonyms are provided for each word. A stemmer than converts these words into stems. After this pre-processing, the target verses or documents are retrieved by matching each word from the updated query. It was concluded that semantic-stemmer based 
TABLE VII: Works based on Qur'anic ontologies.

\begin{tabular}{|c|c|c|c|}
\hline Sr. & Research & Ontology Domain & Technique Applied or Contribution \\
\hline 1 & Al-Yahya et al. [34] & Time domain & Hierarchical system to find synonyms and antonyms of words in Qur'an. \\
\hline 2 & Iqbal et al. [35] & 30th Division of the Qur'an & $\begin{array}{l}\text { Ontology provides authentic contextual meaning of verses. Translation available } \\
\text { in English and Malay. }\end{array}$ \\
\hline 3 & Khan et al. [37] & Animals & $\begin{array}{l}\text { Development of framework to perform semantic queries related to animals in } \\
\text { Qur'an. }\end{array}$ \\
\hline 4 & Ali and Ahmad [38] & Manners and Faith & Development of thematic hierarchy based on authentic source. \\
\hline 5 & Ta'a et al. [39] & Allah, Angels and Unseen & GUI based thematic search system for Qur'an \\
\hline 6 & Alqahtani and Atwell [40] & Complete Qur'an & Merger of existing ontologies and development of AQSST search tool \\
\hline 7 & Ahmed and Atwell [41] & Various concepts but not all & $\begin{array}{l}\text { Development of ontology by merger of existing, extracting original text from } \\
\text { the Qur'an, and help from domain experts. }\end{array}$ \\
\hline 8 & Alqahtani and Atwell [42] & - & $\begin{array}{l}\text { Proposed the idea of existing complete Qur'an ontologies to widen the avail- } \\
\text { ability of knowledge }\end{array}$ \\
\hline
\end{tabular}

technique has retrieved far better results as compared to simple query search. The test was also performed with only semantic based search. However, the evaluation showed that recall for semantic-stemmer based technique were far better.

Alqahtani et al. [48] have discussed various search techniques and tools for Qur'an. Most of these tools have been discussed in this paper. They have evaluated these tools against 13 different parameters in order to see their drawbacks and limitations. The existing search tools can be classified into two main categories which are text-based searching and semanticsearching. Both these categories can be further sub-categorized as shown in Figure 10.

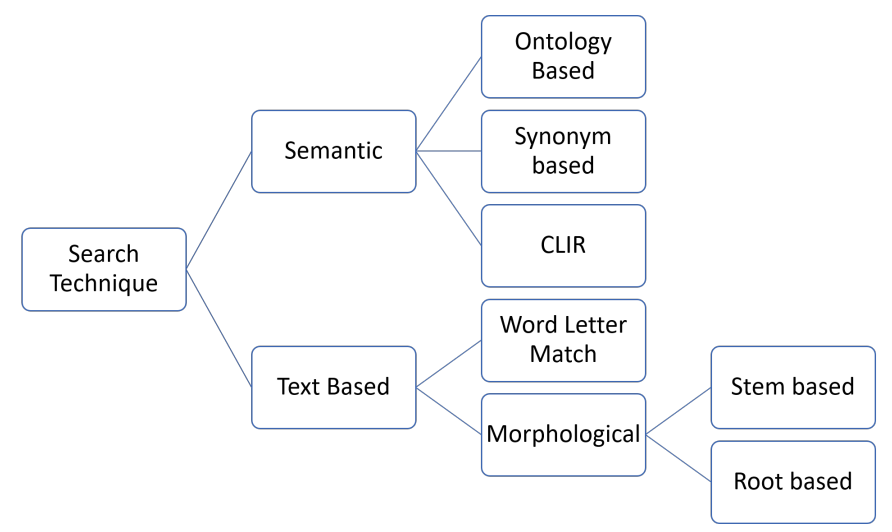

Fig. 10: Types of existing search tools for Qur'an.

The existing tools apply one of these techniques to answer the queries of users. These tools were evaluated at common criteria which encompass search features, precision of results, database size, query and answer type, response time and database contents. The evaluation results can be summarized as follows:

1) Limitation for retrieving all requested information from the Qur'an related to the query.

2) Many tools allow one word based query and do not allow search based on concept, phrases, or topics

3) The ontology-based search tools do not cover all the concepts. Only a few ontologies are covered and thus they fail to deliver results against all concepts
4) None of the tools solves the ambiguity problem of retrieved results. By ambiguity we mean that results for words having same spellings.

5) The tools do not apply modern NLP techniques such as parsing or spell check.

6) These tools do not have Name Entity Recognition especially designed for Qur'anic text.

As discussed in Ontology Based Technology section, Khan et al. [37] proposed a semantic search tool based on ontological approach. However, the ontology does not cover the complete concepts of Qur'an. The proposed ontology covers animals and birds in Qur'an. The ontology was developed after analysis of each verse of the Qur'an. SPARQL query language was used to perform the search. The query is taken in the form of a natural language question in English. Th system converts the question into system specific query format. The questions like "Which animal is used for riding?" are answered correctly. It was also recommended to extend the proposed framework further in a proper search tool that can take input through a GUI and performs search using Qur'anic explanations and Hadith as reference.

Alqahtani et al. [40] proposed a search tool named as Arabic Qur'anic Semantic Search Tool. The tool is based on ontology of the Qur' an and utilizes both information retrieval and semantic search approach. The query entered by the user undergoes various NLP checks such as stop word removal, stemming, and POS tagging. Semantic tags and synonyms are provided each word. The search is first performed using the concepts from the ontology. If no results are retrieved then, search is performed by word matching technique. Finally, the results are provided the score for their relevancy to the query and then ranked before presenting to the user. The tool also deals with ambiguity of results for words having same spelling and provides detailed results with concepts of each word. The tool also addresses the issue of lack of NER for Qur'an.

Shoaib et al. [30] developed a semantic search tool in order to overcome the deficiencies of simple keyword based search system. The framework is developed for Surah Al-Baqarah of the Qur'an (Chapter 2) initially. To perform the semantic search WordNet is utilized, which provides different synonyms and antonyms of words. We know that, a single word can impart multiple meanings, so the query word is allocated a 
single interpretation at the start of the search. The system then searches for the verses that contain the word and followed by the synonym-based search. The retrieved results are returned in a priority order with verses retrieved for exact synonym-based search first and the weak synonym-based results in last. $80 \%$ more relevant results were achieved as compared to simple query search.

To overcome the irrelevancy issue and poor retrieval results for keyword based search and domain specific ontology issue in semantic search Alqahtani et al. [31] designed Qur'anic Semantic Search Tool (QSST). The system aligns existing ontologies to provide better results. Initially, the system performs concept-based search with the help of ontology and then it performs search by word matching technique. This technique achieves the goods of both worlds, keyword and semantic search. The results are ranked and redundant verses are eliminated.

Safee et al. [49] have also reviewed the strengths and weaknesses of existing Qur'anic search tools. They also designed a new ontology by aligning Qur'an ontology and medical domain specific ontology. Majority of the ontologies developed for the concept-based search for Qur'an, as discussed earlier, are domain specific. They do not cover the whole Qur'an. Only a few ontologies cover the whole Qur'an but they do not cover all the concepts and thus fail to retrieve results for complex query. In this work, ontology for Qur'an taken form Qur'an ontology.com has been aligned with one of the medical field specific ontology. Arabic WordNet is used to perform lexical matching between two ontologies. Finally, the same concepts are matched from one ontology to another using a fuzzy algorithm. The framework has two components, loading and matching component. The former component will make objects for the ontologies and the later will combine by mapping similar components. The algorithm works by matching some person from the Qur' an ontology to some human disease from the medical ontology. The results of the experiment were not great and output accuracy was quite low. The main reason of the failure is that there was inconsistency in the integrated ontologies. Future target is to fix the inconsistency issue and develop an intelligent Qur'anic search system.

The overall summary of the section is presented in Table VIII.

\section{F. Classifier Systems and Qur'anic NLP}

Al-Kabi et al. [50] have developed an automatic text categorization (ATC) tool in order to classify the verses of the Qur'an. The verses are classified under the various subjects designated by the Islamic scholars, such as Faith (Iman), Prayer (Salah) and Pilgrimage (Hajj), etc. The tool has been devised using Microsoft Visual Basic. The algorithm is quite simple and easy. Initially desired verse is selected from a surah. Then each verse is normalized into features. For each feature, verses are searched from the corpus that contains that feature or word. With the help of all the verses extracted, the relevant subject of the initial verse is allocated. Allocation of subject is done by calculating the subject percentage for each feature in the verse. The subject with highest percentage is then tagged to that particular verse. The prototype has been developed for Surah Al-Fatihah (Quran Chapter 1) and Surah Yaseen (Quran Chapter 36). The accuracy of the results reaches up to $91 \%$. To increase the accuracy further, corpus is to be increased and once the whole Qur'anic corpus is included in the project, the precision will be quite high.

Ontology developed by Ta'a et al. [38] is also helpful in classification of Qur'anic verses on the bases of themes. Verses belonging to Manners and Faith theme are classified. Subthemes are available within these classes. This hierarchical approach helps in classification of Qur'anic verses at various levels. This thematic classification can be helpful in studying and searching the various themes discussed in Qur'an.

\section{G. Topic Extraction/Categorization and Qur'anic NLP}

Alhawarat et al. [14] have applied LDA for the topic modelling. It is one of the most popular probabilistic method used in NLP for topic modelling. LDA method was chosen on the previous studies that outperforms K-means clustering in most of the experiments. The experiment was performed on the corpus of Surah Yousaf (Chapter 12) of the Qur'an. The possible list of topics was already defined. The probability of a word belonging to a particular topic is defined with the help of equation given below:

$$
P\left(w_{i}\right)=\sum_{j=1}^{T} P\left(w_{i} \mid x_{i}=j\right) P\left(x_{i}=j\right)
$$

Here $w_{i}$ is the $i^{t h}$ word of a document and, $x_{i}$ is the $i^{t h}$ topic. The experiment was performed on verses based on original words of surah, their stem and their roots. However, it was observed that the results with roots were totally not acceptable. Various experiments were performed with variations of LDA. The results showed that except a few, most of the topics included a mixture of more than one topic and did not provide correct context. It was concluded that LDA can be a better method for routine NLP topic modelling but for the Qur'an, the model does not work.

Hassan et al. [51] also used machine learning for topic categorization but they adopted supervised learning technique. They performed the text categorization of Malay translation of Qur'anic verses using KNN algorithm. In KNN algorithm, the model is trained on data and then test data is allocated a label depending on the similarity with neighbors from training data. For the experiment, vectors of verses were created after preprocessing. Training was done on 800 verses belonging to seven different topics and later test was performed on 200 verses. The recall for seven categories ranged from 0.74 to 0.90 . The low recall for two categories was due to common words involved in both categories. The results were great in the sense that recall achieved is on higher side and also that algorithm is quite easy as compared to LDA as discussed earlier. The results can further be improved by increasing the dataset.

Alshammeri et al. [52] have used the approach of embeddings for the topic modelling of Qur'an. For the experiment, instead of using word vectors, document vectors were created 
TABLE VIII: Search Systems

\begin{tabular}{|c|c|c|c|}
\hline Sr. & Research & Issue Addressed & Technique Applied or Contribution \\
\hline 1 & Hammo et al. [46] & $\begin{array}{l}\text { Lower accuracy in Qur'an verses search system based } \\
\text { on a word }\end{array}$ & $\begin{array}{l}\text { Query expansion using search based on all variants of } \\
\text { query word and its synonyms. }\end{array}$ \\
\hline 2 & Al Gharaibeh et al. [47] & $\begin{array}{l}\text { Unambiguity in conventional methods for Qur'an search } \\
\text { engine tools }\end{array}$ & $\begin{array}{l}\text { Development of search engine based on text, stem and } \\
\text { synonym searching using Formal method and } \mathrm{Z} \text { notation }\end{array}$ \\
\hline 3 & Yunus et al. [32] & Low accuracy of results for query based search & $\begin{array}{l}\text { Developed CLIR search tool for Arabic, Malay and } \\
\text { English with the aid of semantic and stemming approach }\end{array}$ \\
\hline 4 & Alqahtani and Atwell [48] & $\begin{array}{l}\text { Evaluation of drawbacks of existing Qur'anic search } \\
\text { tools }\end{array}$ & $\begin{array}{l}\text { Evaluation of search engines based on criteria such as } \\
\text { search techniques, ontology, database size, etc. }\end{array}$ \\
\hline 5 & Khan et al. [37] & Concept based queries for Qur'an & $\begin{array}{l}\text { Ontological approach. Animal domain ontology is de- } \\
\text { veloped. }\end{array}$ \\
\hline 6 & Alqahtani and Atwell [40] & $\begin{array}{l}\text { Concept based search, lack of comprehensive ontology, } \\
\text { NER for Qur'an }\end{array}$ & $\begin{array}{l}\text { Developed AQSST, which performs ontology-based } \\
\text { search aided by keyword search. }\end{array}$ \\
\hline 7 & Shoaib et al. [30] & Low accuracy of results with simple query & $\begin{array}{l}\text { Semantic search tool based on WordNet. Verses are } \\
\text { searched for the words in a particular sense }\end{array}$ \\
\hline 8 & Alqahtani and Atwell [31] & $\begin{array}{l}\text { Low accuracy of keyword search and domain specificity } \\
\text { of Ontology based Search }\end{array}$ & $\begin{array}{l}\text { Developed QSST search tool that has alignment of } \\
\text { ontologies for better conceptual results. QSST also } \\
\text { supports word matching technique for search }\end{array}$ \\
\hline 9 & Pitchay and Ridzuan [49] & $\begin{array}{l}\text { Review of gaps in existing Qur'anic search tools and } \\
\text { development of medical ontology }\end{array}$ & $\begin{array}{l}\text { Aligning Qur'an upper ontology and medical domain } \\
\text { ontology using fuzzy logics. The accuracy was low and } \\
\text { requires fixes in ontology integration. }\end{array}$ \\
\hline
\end{tabular}

based on original verses of Qur'an. The document vector approach proved to be more useful in order to retrieve the semantically close verses for a given verse. These vectors were then fed as features for a K-Mean clustering algorithm for the topic modelling. All the verses of Qur'an were categorized into 14 clusters. The experiment showed that the clusters based on document level vectors helped in achieving semantically rich topics for Qur'an.

In contrast to machine learning methods, Yauri et al. [53] categorized the topics using ontology. Ontology is most widely used method to make computers interpret and understand concepts. Since, knowledge and topics are usually centered around a particular concept, this can be a useful method for topic categorization. The framework was developed using the already-built Leeds University ontology that only discussed nouns of Qur'an. This ontology was further extended in this project and concepts of acts were introduced. Ontology was developed using Protégé in which different concepts are linked in a hierarchy fashion where most general concept is at top. At top there are 15 topics such as Living creature, location and religion. Under the umbrella of these concepts more specific concepts are defined. Due to this semantically rich categorization, verses belonging to a particular topic can be easily extracted as each verse is marked under some particular concept or topic.

\section{H. Knowledge Extraction and Qur'anic NLP}

Saad et al. [54] have described a set of rules that can be helpful in the extraction of knowledge from the Qur'an based on English translation. They have adopted ontology as a source of knowledge extraction for Qur'an. This ontology is based on three layers, which are meta concept of the Qur'an, domain ontology layer of Salah, and the last layer that bridges the first and the second layer.

Machine learning methods are widely used in a number of tasks. Siddique et al. [55] adopted unsupervised machine learning approach and used LDA to discover the thematic structure of the Qur'an, which will be helpful in knowledge extraction based on some particular theme. They considered one surah of the Qur'an as a document and discovered the themes in it. The original Arabic Qur'an was used for the experiment. After the initial NLP preprocessing, data was reduced to 24 surahs with 417 terms only out of 114 surahs. The reason for doing this reduction was to remove the less frequent terms that can hamper the results. As described in previous section LDA works by allocating topics to different words in a document. The topic with the highest probability is assigned to the document. The experiment results showed that the model correctly classified Meccan and Medinan Chapters of the Qur'an based on the difference of words. The results are promising and proved that LDA can be applied for topic based knowledge extraction from the Qur'an.

Mohamed et al. [15] used the supervised machine learning approach that is decision tree classifier, in order to find the answers of questions from the Qur'an. The model was devised for original Arabic Qur'an. The system was backed by a Qur'an ontology developed by the integration of two different ontologies. The ontology covered 1200 concepts. The framework converts question and its possible answers to vectors and then finds the semantic relativity of the answers' vectors to the question vector using decision tree classifier. Keyword matcher is also used to support the results. These vectors are then classified into direct, related and irrelevant classes. Training was performed on Fatwa questions taken from a website as these are the usual questions asked by the people. The testing results showed that accuracy reaches up to $74.53 \%$ The results can be further enhanced if only direct or non relevant answers are chosen, as the relevant class is generic and it can have answers from both categories.

Ontology can also be used for knowledge extraction. As we have seen earlier, ontology is a conceptual dictionary 
that categorizes different concepts under a hierarchy. Yauri et al. [53] have adopted the Web Ontology language (OWL) to perform conceptual search on the verses. They reused the ontology developed by Leeds University but introduced more concepts in it related to various acts and worships in Islam. Although it does not cover all the concepts discussed in the Qur'an, but with the help of description logic query system more complex queries can be performed as compared to other ontologies developed. The Manchester OWL syntax is used to perform the query. The system extracts semantically rich answers for the queries as the data is linked in an inheritanceconcept system. Although, complex queries can be performed, but the system lacks in providing user friendly interface where a query could be entered in natural language way. However the team focuses to cover this issue in future.

The ontology approach is also adopted by Ta'a et al. [39] but it is more user friendly. Instead of performing some syntax based queries, a graphical user interface allows user to select a particular topic or theme and two sub themes from drop down menus. After the selection of the themes and sub-themes, query can be performed by entering a keyword that retrieves the relevant verses based on pattern matching technique. The results achieved up to $90.4 \%$ accuracy and were also authenticated by scholars. The system provides great results, but it also covers only three themes that are related to Allah, Angels and Unseen. Ahmed et al. [41] worked on improving the number of topics and concepts covered by ontology for knowledge extraction. Their ontology includes merger of previously existing two ontologies, an ontology extracted from the Qur' an and Tafsir and an ontology extracted from the reviews written by scholars on various verses. The information from these three types of ontologies is merged together to form a new broader ontology that covers more concept and is able to answer more queries. The system was able to produce up to $82 \%$ accuracy. The results were further improved up to $85 \%$ by using a PROMPT tool, which helps in merging small and medium sized ontologies.

Both Machine Learning based and Ontology based methods can be applied to extract knowledge from the Qur'an. However, both of them are still under continuous research and improvement phase. Various techniques discussed in this subsection for knowledge extraction can be summarized in Table IX.

\section{Speech Processing and Qur'anic NLP}

All Muslims around the world either Arab or Non-Arab recite the Qur'an. The Qur'an needs to be recited in a proper way and rules called Tajweed. Moreover, many Muslims memorize the complete Qur'an by heart. Therefore, it is the need of the hour to empower Muslims with state-of-the-art speechbased learning solutions for the recitation of the Qur'an. The foundation of this would be a speaker independent automatic speech recognition system for the complete Qur'an. Much work has been done in this area and some of the important work is explained in this section.

Brierley et al. [56] have worked on a set of consonants in the Qur'an that provide the prosodic effect of Qalqalah (vibration). Prosody is the pattern of rhythm that how the voice of the speaker rises and falls while speaking. The tool takes the Qur'an as input and using NLP techniques returns the words in the verses which contain Qalqalah consonants. A tool named Semantic Pathway is used to find out the types of words having Qalqalah effect. It was found out that the most frequent Qalqalah words used in Meccan and Medinan surah are different. Another contribution is the development of pronunciation guide for the Qalqalah words, which will be helpful for the recitation of the Qur'an.

Ibrahim et al. [57] provide a review on techniques used in different steps of speech recognition of Qur'an. There are four major stages in speech recognition and these steps are pre-processing, feature extraction, training and testing. Preprocessing is done to improve the readability of audio data. The techniques used in pre-processing are Endpoint Detection, Noise filtering, Smoothing and Channel Normalization. For features extraction techniques like Linear Predictive Coding, Perceptual Linear Prediction, Mel-Frequency Cepstral Coefficient (MFCC) and Spectrographic Analysis are used. And for Training and Testing purposes Hidden Markov Model (HMM), Artificial Neural Network (ANN) and Vector Quantization (VQ) are used. Authors concluded by their research that for feature extraction the most suitable is the MFCCs method and for training, HMM are most suitable and these are widely used in speech recognition.

Ahmed et al. [58] also explained the same techniques as explained by Ibrahim et al. [57] and also proposed a technique for Qur'anic verses verification. The audio recitations from the verified scholars are stored in the database. For testing any new recitation the audio signal is aligned with the Qur' an text after the preprocessing steps and this is the most challenging part. The MFCC feature vectors of this recitation to be tested is compared with the verified recitations and differences in recitation are notified to the reciter.

Adnan et al. [59] used deep learning approach to address a less solved area of speech recognition. They applied Bidirectional Long Short-Term Memory (BLSTM) model to identify the Qur'an reciter. The model takes recitations of various lengths from five different reciters and extracts the MFCC features from them to feed as an input to BLSTM. The results achieved are exceptional as accuracy reaches up to $99.89 \%$ for identifying the correct reciter for 3 seconds of recitation. These results are far better than other powerful models like SVM that remained below 90\%. The model also surpassed the conventional ANN model that could achieve the accuracy of $91.8 \%$.

Qur'an is a sacred book and it must be recited with utmost care as by minor change in the pronunciation the meaning of that word changes. Mohammed et al. [60] proposed a four staged method for verification of Qur'an recitation using speech recognition techniques. These stages are input preparation, feature extraction by MFCC, audio match and training followed by testing of model using HMM. Matching stage is significant as it will search the MFCC feature of input recitation in the database of already stored authentic recitations MFCC features. If the features match then recitation will be considered authentic. 
TABLE IX: Knowledge Extraction Techniques

\begin{tabular}{clcll}
\hline Sr. & Research & Methodology & Technique Applied & Outcome or Contribution \\
\hline 1 & Siddiqui et al. [55] & ML & Unsupervised learning-LDA & $\begin{array}{l}\text { Correct clustering of Meccan and Medinan Chapters of } \\
\text { the Qur'an } \\
\text { Bayyan: a tool that performs query search and re- } \\
\text { turns answers based on semantic similarity. Accuracy: } \\
74.53 \%\end{array}$ \\
3 & Mohamed et al. [15] & ML & Supervised Learning- Decision tree & $\begin{array}{l}\text { Semantic answers extraction using multi-theme levels, } \\
\text { syntax based query, not user friendly, limited concepts }\end{array}$ \\
4 & Ta'a et al. [39] & Ontology & OWL based knowledge extraction & $\begin{array}{l}\text { Semantic answers extraction using multiple themes, } \\
\text { keyword based query, user friendly GUI, limited con- } \\
\text { cepts, Accuracy up to 90.4\% } \\
\text { Conceptually rich answers extraction, Accuracy: up to } \\
85 \%\end{array}$ \\
& Ontology & OWL based knowledge extraction & Knowledge extraction related to Salah \\
\hline
\end{tabular}

Jamaliah et al. [61] investigated the Tajweed checking system using speech recognition to complement the conventional methods of Qur'anic learning with the latest technology. Authors provide a deep insight into MFCC method for feature extraction and HMM method for classification part of speech recognition. Initial system was tested for Surah Al Fatiha (Chapter 1), which results in recognition rate of $91.95 \%$ on verse level and $86.41 \%$ phoneme level. These results show that the developed system has the potential to be adopted in the education system to support the traditional methods in Qur'anic learning process.

Muhammad et al. [62] developed an intelligent system EHafiz that helps in recitation and memorization of Qur'an. Recitation. The availability of Qur'an experts is not common in the non-muslim countries which hinder in the process of learning and memorizing Qur'an. To develop E-Hafiz MFCC feature extraction is adopted. MFCC features of reciter are compared with that of of experts. Reciters recite verses from the Qur'an in the presence of an expert who points out the mistakes. Expert rectifications are compared with the mistakes pointed out by E-Hafiz system to measure the accuracy. The accuracy of this system on a group of men, children and women is $92 \%, 90 \%$ and $86 \%$, respectively.

Amrani et al. [63] use simplified phonemes in Automatic Speech Recognition (ASR) for Qur'anic recitation. CMUsphinx toolkit in used in the project. Data used is the recitations of first and last 3 surahs of the Qur'an. The audio data is of almost 40 minutes from male speakers. Different training configurations are tried and the best result were obtained at 32 dimensions of the Gaussian mixtures. It was concluded that by using simple phoneme list instead of romanized phonemes, which are difficult to generate for whole Qur'an, it is possible to build an ASR for complete Qur'an by adding more recitations of the renowned reciters to the database.

Abro et al. [64] tried to automate the Qur'an memorization process using speech recognition techniques. For feature extraction MFCC is used and ANN is used for acoustic modelling and pattern recognition. The data set used has twenty utterances of the last surah of the Qur'an (Chapter 114), recited by a fluent reciter of the Qur'an. Dataset for recitations with errors is generated artificially by removing some words from original recitations. Classification of correct and verses with errors is done. Experiments failed to differentiate between the correct recitations and recitations with errors and give false positives. It was concluded that this simple technique is not suitable for automating the Qur'an memorization, And further work is needed to be done.

Yekache et al. [65] discussed the initial steps towards making the Qur'an reader controlled by speech commands. In this regard, they gathered speech data for names of all 114 surah of the Qur'an, some reciters name and some other commands. They adopted HMMs for acoustic model training and used CMUSphinx toolkit for developing this system.

Tabbal et al. [66] presented the delimitation of Qur'anic verses using speech recognition techniques. The amount of Qur'anic recitations available online for free is promising but these do not have verse by verse trimmed. So, there is a need to make an automatic system that trims the recitations of the Qur'an on verse level. The toolkit used in this work is CMUsphinx. The data set is the recitations of Surah AlIkhlas (Chapter 112) by professional reciters and by normal reciters who do not follow the tajweed rules strictly. The mean recognition ratio on 5 professional reciters who recited in tajweed style is $90 \%$ and 8 professional reciters who recited in Tarteel style is $92 \%$. Experimental results on the recitation of normal Arabic speaking 20 males is $90 \%$ and 20 females are $85 \%$.

Al-Bakeri et al. [67] built an ASR for tajweed checking and integrated it into a self-learning environment that must ensure the Qur'an is pronounced correctly as per the tajweed rules. For feature extraction, MFCC is used. HMM is used for acoustic model training and Gaussian mixture density is used to calculate the state emission probabilities. Surah Al-Ikhlas and Surah Al-Rahman (Chapter 55) recited by ten reciters is used as input. Two scenarios are followed, one is the use of phonemes and second is the use of syllables. The use of syllable performs well when the data is small and gives $100 \%$ accuracy for Surah Al-Ikhlas. In results of using phoneme accuracy rate $89.47 \%$ is achieved.

Putra et al. [68] tried to minimize the difficulty in the learning process of the Qur'an using speech recognition and integrated the system with a learning software. For speech recognition, MFCC features and Gaussian Mixture Model (GMM) modelling is used. Interactive multimedia software 
is built in a prototype stage. Accuracy for pronunciation of reciters is $70 \%, 90 \%$ for recitation law and $60 \%$ for a combination of these two. The results show that performance is poor as dataset used is small.

Tabbaa et al. [69] worked on the computer-aided training for learning the Qur'an recitation. HMM-based ASR initially recognizes the recitation phones. Only two classifiers are trained, one for differentiation between emphasized and nonemphasized pronunciation of letter $\mathrm{R}$ and second classifier to discriminate closely related letters. Data set used is the telephone calls on a TV program where a professional reciter recites a page from the Qur'an and then listens to the callers'. The ASR system gives $97.6 \%$ word level accuracy. For phone level classification four different classification algorithms are tested and the best one is chosen for each scenario. These four algorithms are SVM, Neural Network Multi-layer Perceptron (MLP), Bagging and Random Committee. To test the performance of the complete system 60 minutes of audio data from 18 female and 14 male reciters are used. The previously mentioned $97.6 \%$ accuracy is reduced to $84 \%$ if mispronounced phones are considered as word-level error. After integrating the classifier, the accuracy is improved to $91.2 \%$ as it reduced the phone level false positives and false negatives.

Satori et al. [70] studied some fundamentals of Arabic speech recognition using CMUSphinx toolkit. The data set was made in-house by 6 Moroccan male speakers, each of them spoke ten Arabic digits. Each digit is repeated 5 times by each speaker and hence total 300 utterances are there in the data. The mean recognition ratio of the testing experiment on the three male person utterances of these 10 digits is $86.66 \%, 86.66 \%$ and $83.33 \%$ respectively. Hello_Arabic_Digit application is presented so that it would be adopted in the Arabic speech recognition system.

El Amrani et al. [71] investigate the use of simplified Arabic phonemes in building a phonetic dictionary for speech recognition system. Normally Romanized phonemes are used in phonetic dictionaries required to train ASR. The audio data used is the recitations of famous reciters of first and last three surahs of the Qur'an. CMUsphinx toolkit is used and the building of phonetic dictionary consisting of simplified Arabic phonemes from the Qur'anic text is automated through a computer program. Hence, the transcription file, phonetic dictionary and list of phones are automatically generated by the developed program. Experiments have been done with different training settings and the lowest word error rate obtained is $50.0 \%$ and $55.7 \%$ while using $90 \%$ and $80 \%$ of the audio data in training respectively.

Ahsiah et al. [72] propose a tajweed checking system to support the learning of the Qur'anic recitation. The proposed system listens to the reciters' recitation and match it with the recitations of the experts and find out the differences between them and hence tells the mistakes to the reciter. The proposed system used MFCC for feature extraction and HMM for feature classification.

Mohammed et al. [73] investigate the phoneme duration at Madd, Ghunna and some other letter characters. These are some few rules from the important Tajweed rules that need to be followed while reciting the Qur'an. To calculate the duration of Madd and Ghunna in recitation data is collected from the recitations of expert reciters. This system is used to point out any mistakes in Madd and Ghunna rules of any person's recitations. 600 words data is collected by recitations of 10 Reciters. And from the recitations mean duration of each the of the Madd and Ghunna is calculated. The subsection is summarized in Table X.

\section{J. Quranic Corpus and Qur'anic NLP}

Alrabia et al. [74] have contributed to classic Arabic NLP by creating a large classical Arabic corpus of more than fifty and half million words. The corpus consists of six domains and major portion is dominated by religion with $46.73 \%$. They have also performed two empirical studies. Both these studies are dedicated to find the collocations in the classical Arabic. For this purpose they have performed eight statistical association measures. For the first study QAC is chosen. This first study is further broken into two phases. In the first phase, mean average precision (MAP) is measured for the association rules by making least frequent part of collocation node while in the second part the most frequent part is made the node. For Qur'anic corpus, collocation extraction with least frequent word as node gave better results. For choosing most frequent word as node, the MAP for all association results drop significantly, because more frequent part will have more association with other words. There is great drop in MAP for log-likelihood, although it shows great result for first phase. For the second empirical study, association measures were checked on the newly developed large corpus that is KSUCCA. The aim of experiment was to see if the association measures change by changing the size of corpus or not. It was observed that scores for all the measures dropped quite significantly. However, it was observed that MI.log-frequency and log Dice are the most suitable in terms of their MAP for both small and large corpus. The results of the eight association rules and their comparison is shown in Table XI:

\section{K. Q/A Systems and Qur'anic NLP}

Hamed et al. [75] developed a question answering system using artificial neural network to classify the verses related to pilgrimage and fasting. The dataset used for this tool is the English translation of the second chapter of the Qur'an. The tool consists of three components. The first component is the question analysis module, which performs preprocessing on the user query to clean it and then performs the expansion using wordNet and Islamic terms. Document retrieval module is the second component, which is based on neural network. Model is trained in this component at 150 verses belonging to three categories of fasting, pilgrimage and none of these. Final component is the answer selection module. With the help of first module where question was converted into machine interpretable form, the relevant verses are retrieved using $\mathrm{N}$-gram matching technique. The relevant verses are ranked where the verse with most matched words with the question are placed at the top. The model has provided great results. 
TABLE X: Speech Recognition Work for Qur'an

\begin{tabular}{|c|c|c|c|}
\hline Sr. & Research & Issue Addressed & Technique Applied or Contribution \\
\hline 1 & Brierley et al. [56] & prosodic effect of vibration of words for Qur'an & $\begin{array}{l}\text { Investigation of various vibration words in Qur'an and } \\
\text { pronunciation guideline development }\end{array}$ \\
\hline 2 & Ibrahim et al. [57] & Review of techniques for speech recognition & $\begin{array}{l}\text { Concluded that MFCC and HMM are the best method } \\
\text { for feature extraction and training respectively }\end{array}$ \\
\hline 3 & Ahmed and Abdo [58] & Review of techniques for speech recognition & $\begin{array}{l}\text { Description of various methods involved in speech } \\
\text { recognition for Qur'an recitation }\end{array}$ \\
\hline 4 & Qayyum et al. [59] & Identification of the Qur'an reciter & $\begin{array}{l}\text { Used deep learning for speech recognition and identifi- } \\
\text { cation with } 99.89 \% \text { accuracy }\end{array}$ \\
\hline 5 & Mohammed et al. [60] & $\begin{array}{l}\text { Integrity and authenticity of the Qur'an in recitation on } \\
\text { social media }\end{array}$ & $\begin{array}{l}\text { Speech recognition methodology proposed based on } \\
\text { MFCC and HMM }\end{array}$ \\
\hline 6 & Jamaliah Ibrahim et al. [61] & Tajweed checking & $\begin{array}{l}\text { Tajweed checking with speech recognition based on } \\
\text { MFCC and HMM }\end{array}$ \\
\hline 7 & Muhammad et al. [62] & Qur'an memorization with correct Tajweed & $\begin{array}{l}\text { Speech recognition based system with accuracy above } \\
86 \%\end{array}$ \\
\hline 8 & Amrani et al. [63] & Correct Qur'an recitation identification & Use of simlified phonemes in Speech recognition \\
\hline 9 & Abro et al. [64] & Qur'an memorization & Neural network based speech recognition using MFCC \\
\hline 10 & Tabbal et al. [66] & Delimitation of verses using speech recognition & $\begin{array}{l}\text { Speech recognition of Verses from various reciters using } \\
\text { CMUsphinx tool }\end{array}$ \\
\hline 11 & Al-Bakeri and Basuhail [67] & Correct Tajweed of the Qur'an & $\begin{array}{l}\text { ASR based on MFCC and HMM using phonemes and } \\
\text { syllables }\end{array}$ \\
\hline 12 & Putra et al. [68] & Qur'an recitation learning & $\begin{array}{l}\text { ASR based on MFCC and GMM. Prototype gives } \\
\text { up to } 60 \% \text { accuracy combined for pronunciation and } \\
\text { recitation laws. }\end{array}$ \\
\hline 13 & Tabbaa and Soudan [69] & Qur'an recitation learning & $\begin{array}{l}\text { HMM based ASR for classification of errors in recita- } \\
\text { tion using different AI algorithms. }\end{array}$ \\
\hline 14 & Satori et al. [70] & Arabic speech recognition & $\begin{array}{l}\text { Development of "Hello Arabic" App with accuracy of } \\
83.33 \% \text { for Arabic ASR }\end{array}$ \\
\hline 15 & El Amrani et al. [71] & $\begin{array}{l}\text { Investigation use of simplified Arabic phonemes for } \\
\text { speech recognition }\end{array}$ & $\begin{array}{l}\text { Use of the Qur'anic phonemes with CMUsphinic } \\
\text { toolkit. }\end{array}$ \\
\hline 16 & Ahsiah et al. [72] & Correct Tajweed checking & $\begin{array}{l}\text { ASR based on MFCC and HMM for the identification } \\
\text { of mistakes during recitation }\end{array}$ \\
\hline 17 & Mohammed et al. [73] & $\begin{array}{l}\text { Mistakes identification during particular letter recita- } \\
\text { tions of the Qur'an }\end{array}$ & $\begin{array}{l}\text { Mean time of recitation calculation of "Madd" and } \\
\text { "Ghunna" to estimate the correct duration of their } \\
\text { recitation. }\end{array}$ \\
\hline
\end{tabular}

TABLE XI: Performance of algorithms against corpus

\begin{tabular}{lcc}
\hline & \multicolumn{2}{c}{ MAP with } \\
\cline { 2 - 3 } Measure & Qur'anic Corpus & KSUCCA \\
\hline MI.log-freq & $76.68 \%$ & $37.02 \%$ \\
Log Dice & $72.64 \%$ & $35.12 \%$ \\
MI & $61.44 \%$ & $5.19 \%$ \\
T-score & $68.70 \%$ & $14.92 \%$ \\
Raw Frequency & $67.26 \%$ & $13.39 \%$ \\
Minimum Sensitivity & $72.77 \%$ & $31.72 \%$ \\
Log-likelihood & $76.66 \%$ & $26.10 \%$ \\
MI3 & $77.01 \%$ & $34.12 \%$ \\
\hline
\end{tabular}

The F-score of verses classification is $90 \%$ and the answers retrieved by the tool achieved the F-score of nearly $87 \%$.

Al-Bayan, the question answer system developed by Mohamed et al. [15] uses supervised machine learning approach and keyword matching. The system provides the answer by a complex system, which makes it sure that answered returned is semantically related to the question. The system makes a semantic relatedness check by calculating cosine similarity between question and answer vectors. At second stage it calculates the keyword matching score. These two scores are used as an input to the decision tree that calculates if the answer falls in direct, related o irrelevant category. The tool was evaluated on common Fatwa questions and answers.

Hamoud et al. [76] have contributed by developing a corpus that consists of questions and answers related to knowledge of the Qur'an. The corpus contains 1000 questions and answers in Arabic and 500 in English language. To make a corpus or dataset related to the Qur'an requires extra care about the authentication of information and knowledge as it is a divine book. Four sources were used to develop the corpus. A large set of questions and answers was retrieved from different websites. This data is important as it is closer to the people asking various questions related to Islamic concepts. Some questions are retrieved from the Qur'an itself. Third source is the questions asked by the Muslims from scholars of Holy Mosque in Makah and the fourth source is from a survey. All the data collected is merged and unified and is made useful by cleaning it. This huge effort can prove very useful in developing tools and platforms that provide authentic and relevant answers to the people efficiently. The corpus has not been made public yet as the work continues to enhance the dataset by creating variants of current questions. 


\section{Interface Systems and Qur'anic NLP}

ElSayed et al. [77] have designed an interface system for the people who are not expert at database. The system takes input from user in the form of Arabic language query. Most of the systems have knowledge stored in their databases in the form of structured data that is returned upon query. This query has to be in specific syntax of the database system. The designed system allows the user to input the question in Arabic language and then converts that question into specific query and returns the output. The system can be divided into two parts. First part is NLP-based. After the user inputs his query using a graphical user, there is a lexical analyzer scans the whole sentence and perform spelling check too. The Arabic query is then converted into its English translation. A parser converts the whole sentence into structured parts in order to make it easy for computer to understand. After this translation, the second part comes into play. SQL generator converts the English sentence to a resembling SQL query. Finally this query is applied on the database and the results are returned to the user. The database consists of Qur' anic chapter, verses, words and $J u z$. There are two types of query modes, imperative mode and question mode. Former starts with an imperative verb and the later is an interrogative style questioning mode. The system currently retrieves answers to simpler queries like "Which surah contains the word Allah?"

\section{Authentication/Verification and Qur'anic NLP}

Internet is the source of information in the 21 st century. There is a large amount of data that is available on internet today and is increased at exponential rate on daily basis. However, this data and information can be correct as well as incorrect. So, one has to be very careful while browsing and searching information. Anyone can post anything he wishes and that can be read by anyone. Same is the case with Islamic information. Many people write and discuss Islamic issues online. In these issues many a times a Qur'anic verses and Hadith are quoted as reference. It has been observed that, many a times the quoted references are either incomplete, incorrect or totally out of context. This leads to complete misinformation. Special care is required when it comes to referring the Qur'anic verses. As it is the Holy Book of Allah and there is no change expected for even a single letter in the whole book. Muslims around the world try their best to make sure that there is no mistake while quoting Qur'anic verses online. However, incorrect quotation can rise due to multiple reasons. Some times a word or letter may be missed mistakenly while typing or copying and some times incomplete verses are quoted because of Islamophobia. For example, it has been observed that, after war on terrorism began, a Qur'anic verse was half quoted by many people, portraying that Qur'an persuades all the Muslims to fight non-Muslims in the name of Allah. Half Quoted verse with its full version is shown in Figure 11. There is need of authentication tools that can verify the online available Qur'anic quotes in order to provide the true knowledge of the Qur'an to everyone.

Alshareef et al. [78] have designed a tool to verify the authenticity of Qur'anic verses quoted online. Qur'an is either

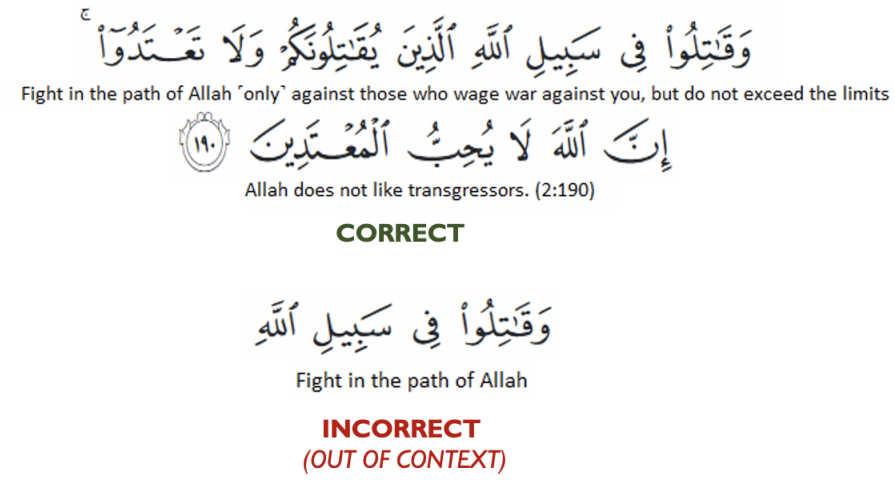

Fig. 11: Correct and incorrect quotation of Qur'anic Verse 2:190

quoted in different issues being discussed online or there are online platforms that provide utility to read Qur'an online. It is important that all these Qur'anic texts should be correct. The authentication checker model consists of two parts, which are Qur'anic quote filter and Verifier. In filter, the quote to be verified, is inserted in the system and then diacritics and symbols are removed from it. After that the verifier part checks if the quoted verse is in the Qur'an or not. If the word by word verse is matched then it marked as correct. If it is a partial quote or if two verses are quoted without full stop, they are considered incorrect because both these cases change the meaning. In case, no verse matches exactly, the system checks for the nearest possible verses in Qur'an and returns them. If there is no verse similar to the quoted one, then the input quote is marked as incorrect. The system checks for the similar verses and exact matches using SQL query. The tool is great in regards of checking authenticity of verses. The future plan is to integrate to online web so that it can accessed by internet users and they can verify the quotes they are reading.

Alsmadi et al. [79] have also developed an online tool that can help in checking the authentication of Qur'anic verses available online. The tool consists of two parts. The first part is used for information retrieval and the other part is used to check the authentication of the retrieved verses against a standard relevant verse. The information retrieval part basically consists of a web crawler. Web crawler works by finding the queried text at online websites and then returns the relevant pages. In this tool, a correct verse is given as a query and the crawler then retrieves the top ten pages returned from the google. These pages include both Islamic and non-Islamic pages. The verses provided by these pages are then checked with the verifier system. The verifier uses a distinct method that is of using hashing algorithm to verify the retrieved verse. Hashing algorithm works by returning a unique Unicode to the given input. MD5 algorithm was chosen because of its popularity. It was also verified if font size and color affect the code for same input or not. After all the checks, the MD5 algorithm was applied. The algorithm is great in the sense that it returns a completely different hashing code even on change of single character or diacritic. The experiment was performed on one of the websites and many errors were found in different 
verses.

\section{N. Crowdsourcing and Qur'anic NLP}

Crowdsourcing is one of the most popular methods adopted worldwide for NLP tasks. Datasets are built with the help of public. In this way a large number of inputs are received and there is variety in data too. This particular method is also adopted for creating NLP datasets, tagging and annotations tasks. Crowd sourcing help achieving the goal in much efficient way. A similar sort of approach can also be adopted for Qur'anic NLP. The contribution that can be achieved by crowdsourcing can include word tagging, similarity checks, annotations, POS tagging and many others. However, crowd sourcing for Qur'anic NLP can differ from other NLP tasks because, a lot of care is required in this case as Qur'an is a Holy religious book of Islam and any wrong input can lead to false information.

Zaghouani et al. [80] have performed an experiment to see if crowdsourcing can be beneficial for Qur'anic NLP or not. They used Amazon Mechanical Turk (AMT) to perform annotations for Qur'an. There are many crowdsourcing platforms available, but AMT is the most widely used for such tasks. There are many workers on the platform who get paid for the problem they solve. Keeping in view that Arabic is not an easy language, the questions were asked with multiple choices, so that the efficiency may be improved. Two different tasks were chosen, POS tagging, and grammatical case endings. For the grammatical case endings, 100 words were chosen from chapter 23, and for POS tagging, 200 words were chosen from the same chapter. Since, such tasks are not easy for non-Arabs and even some of the tasks are even difficult for the expert Arabic linguists, therefore initially a screening test was also taken and only high performer were allowed to perform the tasks. Out of 137 workers only 24 could pass the test and among them 17 workers could perform annotation. This low number of workers doing the annotation show that Arabic NLP and especially Qur'anic, is not an easy task. The accuracy for grammatical case ending was 50\% and for POS tagging it was $63.9 \%$. The results were benchmarked with QAC. The results proved that crowdsourcing is not a good option for Qur'anic or Arabic NLP. It can be concluded with this experiment that crowdsourcing can not be directly applied in this case and tasks related to Qur'an can only be done with the help of experts.

\section{QUR' ANIC NLP TOOLS \& RESOURCES}

In this section we will highlight the tools that have been used in various Qur'anic NLP tasks. There are many tools and platforms that have been utilized in one way or the other but the tools covered here are those that are directly affecting the contributions to Qur' anic NLP.

\section{A. QurSim Corpus}

Sharaf and Atwell [81], is a large Qur'anic corpus with similar and related verses linked together. This corpus is useful for NLP tasks such as the automatic similarity and relatedness detection in short texts as well as machine translation and paraphrase analysis. The corpus includes more than 7,600 pairs of related verses collected from multiple scholarly sources. The dataset was incorporated with a query pages online to allow the visualization of a given verse and its network of the related verses.

\section{B. Quranic Proposition Bank}

In recent years and in order to address the challenges of Natural Language Understanding, [82] created the English Propbank which is a corpus annotated with verbs and their arguments. This corpus was used in the automatic Semantic role labeling (SRL). Later on, [83, 84] created the first Arabic Propbank which was followed by a Qur'anic Propbank [83]. The Qur'anic Propbank was based on Qur'anic Arabic Dependency Treebank (QATB) [85].

The Qur'anic Arabic PropBank (QAPB) is a unique resource as it increased the coverage of the Arabic Propbank by adding the Qur'anic Arabic variety and the semantic usage of classical Arabic religious text and a poetic literary Arabic. to create their corpus, the authors used an Arabic root meaning tool as a reference tool in order to identify the multiple possible meaning of the verbs in the Qur'an.

\section{Annotation Tool}

BAMA is an annotation tool developed in 2004 by Linguistic Data Consortium, the trustees of the University of Pennsylvania. BAMA performs annotation of Arabic text by tagging POS [86]. This tool has been used in the automatic morphological annotation phase of the Qur'an by Dukes et al. [21] with few modifications. BAMA performs the tokenization of the text and the segmentation of words into prefix, stem and suffix. The tool then performs analyses on theses segments and allots POS. Tool also helps in analysing noun case endings, verb moods, vowels and diacritics. BAMA can be helpful in grammatical tasks related to the Qur'an but care must be taken as this tool has been developed for MSA and not for the Qur'an in particular. Many words of classical Arabic Qur'an are not available in BAMA [21].

[87] presented a methodology to annotate conceptual coreference and text Mining the Qur'an. The raw Arabic text of the Qur'an was divided into several morphological units using the Qur'anic Arabic Corpus (QAC).

Later on, Information Retrieval (IR) techniques were used to convert and index the Qur'anic terms. In total, approximately 24,000 pronouns were annotated with their references. These list of referents were organized into more than 1,000 ontological concepts. This data set is helpful in particular for NLP tasks such as the automatic co-reference resolution.

\section{Querying Tools}

SPARQL is a query language used to perform queries on RDF [88]. RDF is a database for semantic web, which is an extension of world wide web. RDF stores the structured and semi-structured data of websites so that it can be queried for useful purposes. SPARQL is similar to SQL language 
SPARQL has been used by Sherif et al. [27] where they have stored Qur'an data in RDF format. The purpose of storing data in RDF is to make it usable for many online platforms. Khan et al. [37] have also used SPARQL query language for the semantic search of the the Qur' an in English language. SQL is a structured query language that is used to perform queries on database [89]. Unlike, SPARQL, it is not designed for semantic web. SQL can be used to retrieve from and store to database. SQL has been used in many search applications developed for the Qur'an. Qur'any Explorer is a comprehensive tool available online that covers the various concepts and themes found in the Qur'an created by Noorhan Abbas and Eric Atwell. ${ }^{3}$.

The corpus of Qur'any Explorer is linked to an ontology taken from from Mushaf Al Tajweed which is considered an expert source. The ontology cover approximately 1200 Qur'anic concepts. Scholars can use the Qur'any ontology browser to find a given concept and a display the the verses related to the concept selected accurately. Qur'any was implemented by using several technologies such as Google Python AppEngine, the NLTK Python Natural Language ToolKit, XML and AJAX JavaScript and Yahoo! User Interface Library.

\section{E. Tools for Ontology}

Protégé-OWL is an open source editor for Protégé framework, which is used to develop and edit ontology systematically [90]. OWL is capable of exploiting features of Protégé such as visualization, storage formats and user interface [91]. Protégé-OWL itself is developed in Java. This technology has been utilized by Ta'a et al. [39] in development of ontology for the Qur'an. Since it is an open source tool, it can be helpful in developing conceptual search system based on ontology.

Natalya et al. [92] developed a set of tools for managing multiple ontologies. IPROMPT tool is one of these tools used for merging two ontologies. The tool provides guidelines to the user in each step to make the correct merger. It also provides suggestions in order to avoid inconsistencies and errors. The other tool is ANCHORPROMPT, which finds correlation between concepts described in ontologies to be merged. There have been various ontologies developed for the Qur'an but most of them are partial. Ahmed et al. [41] merged the partial ontologies using PROMPT tools and achieved a single conssitent ontology with broader range of concepts.

\section{F. Speech Recognition Tool}

CMUsphinx is an open source toolkit developed by Carnegie Mellon University. It is a leading speech recognition toolkit adopted in various speech applications [93]. It consists of four components used for speech recognition and training acoustic models. The tool contains HMM inside it for the speech recognition. CMUSphinx has been used in many speech recognition applications that have been developed for the Qur'an. Most of these applications are focused on correct Tajweed.

\footnotetext{
${ }^{3}$ The Qur'any Ontology browser is accessible online at:
}

\section{G. Crowdsourcing Tool}

AMT is a crowdsourcing platform by Amazon that helps individual and companies to outsource their work [94]. AMT is mostly used for the survey tasks in which people are paid for their contributions. This helps in having data collected from different sources in short period of time. Crowd sourcing can also be utilized for developing datasets for Qur'an NLP tasks. Zaghouani et al. [80] used AMT to see if it is beneficial to use this crowdsourcing platform for Qur' anic NLP tasks. However, the results were not satisfactory as the task was related to the complex domain of grammar that requires expertise. However, AMT can be used in tasks related to Qur'anic NLP that do not require much skills such as collection of recitations from people, survey related to memorization of the Qur'an, or some other generic Qur'an-related survey.

\section{H. Qur'an Translation Resource}

Tanzil is an open source platform that not only provides Qur'anic Arabic unicode for various applications but also provides translations in many languages [95]. There are multiple translations available in each language provided by different translators. The translation can be downloaded and used in Qur'anic NLP applications. The translations can be downloaded in different formats.

Another valuable repository dedicated to application developers is the Qur'andatabase.org ${ }^{4}$ as they can easily download 104 translations of the Qur'an in multiple formats such as plain text, CSV, XML, MSQL among other formats.

\section{Qur'an Corpus Resource}

QAC has been discussed as a contribution in this paper but it has also been used as a resource in [25] and [27]. QAC is a rich corpus which can be especially used in tasks where annotated Qur' anic data is required. QAC provides word level grammar, syntax, and morphology [20]. The corpus is significant as the annotations have been manually verified by volunteers and experts.

Table XII summarizes the tools used for Qur'anic NLP tasks.

TABLE XII: List of Tools used for Qur'anic NLP tasks

\begin{tabular}{cll}
\hline Sr. & Tool & Purpose \\
\hline 1 & AMT [94] & For crowdsource work \\
2 & BAMA [86] & Morphological annotation of Qur'anic words \\
3 & CMUsphinx [93] & Speech recognition applications of the Qur'an \\
4 & PROMPT tool [92] & Ontology merging tool \\
5 & Protégé-OWL [90] & Tool for Ontology development \\
6 & QAC [20] & For annotation rich corpus of Qur'an \\
7 & SPARQL [88] & For performing queries \\
8 & SQL [89] & For search applications \\
9 & Tanzil [95] & For Qur'anic Translations \\
\hline
\end{tabular}

The timeline for milestones related to Qur'anic NLP are shown in Figure 12. This timeline is as per the survey conducted in this paper.

\footnotetext{
${ }^{4} \mathrm{http}: / / q u r a n d a t a b a s e . o r g /$
} 

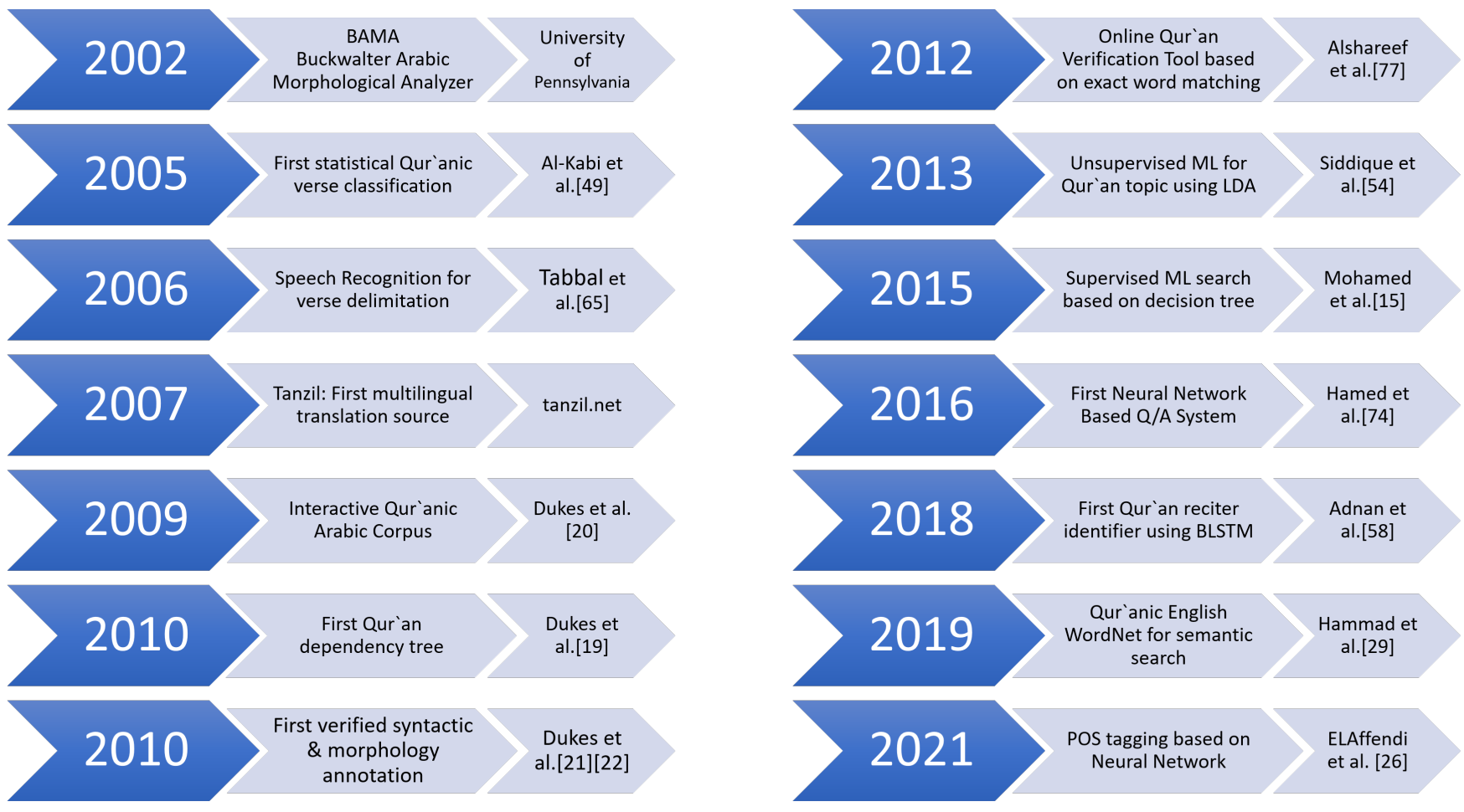

Fig. 12: Timeline with respect to major milestones based on Qura'nic NLP survey

\section{Caveats and Potential Pitfalls in QuR' AniC NLP RESEARCH}

The matter of using technology to obtain understanding of religious texts is a sensitive one. Languages are well-known to be ambiguous and Arabic language in particular is known for its eloquence, conciseness as well as richness. The same word can often have many different meanings-e.g., the Arabic word "min" is said to have at least 15 different meanings ${ }^{5}$ According to Islamic scholars, the correct understanding of Qur'an can only be obtained by knowing both the context (both grammatically and also chronologically in terms of how and when the verse was revealed). For a long time, Qur' an was not translated to other languages because Arabic is assumed to be essential for understanding the Qur'an-even though now many "translations of the meanings" of the Qur' an have been written for pragmatic reasons that dictate dissemination of the meanings of the Qur'an.

Making a mistake in misunderstanding the nuances of Qur'an can have grave consequences. In the Islamic tradition, an in-depth knowledge of the Arabic language is one of the keys to the understanding of the Islamic principles and laws. In the Islamic tradition, it is commonly assumed that to attempt a translation (tarjumah) or an elaboration (tafsir) of the Qur'an, one needs to master many sciences including the Arabic grammar (ilm al-nahw), morphology (ilm al-sarf), rhetoric (ilm al-balaghah), the causes of revelation (asbab alnuzul), etymology (ilm al-ishtiqaq). There are authentic reports of the Prophet of Islam admonishing those people who speak

\footnotetext{
${ }^{5}$ Ibn Hisham's famous Mughni al-Labib, an exhaustive compendium of Arabic prepositions and particles, lists fifteen possible meanings of the preposition "min" when used in a sentence [96].
}

in matters of Qur'an from their opinion without due diligence and educational pedigree. ${ }^{6}$

Despite tremendous progress and recent successes, NLP technologies and computer translation still have a long way to go [97]. This is particularly the case for low-resource languages such as Arabic. Arabic NLP tools particularly for Qur'anic Research needs to have humans-in-the-loop and algorithmic explanations and understanding need to examined and verified by human scholars. Arabic NLP can however still play a strong role. For example, it can facilitate tasks such as search, information retrieval and help humans in performing these quickly and at scale.

In this section, we highlight some caveats of taking a AIbased NLP approach to Qur'anic research:

1) We should be wary of using the results of these models without involving subject-matter experts particularly for results that are not aligned with previous scholarly interpretations and results. Any result that goes contrary to the consensus of early scholars should be rechecked and if it still remains unchanged, then we should scrap it. This is necessary because notwithstanding the great advances in AI-based NLP, and the use of the term "deep" in "deep learning" and in "deep neural networks", the solutions do not currently provide deep human level understanding and their results remain shallow [97]. That means, even in the future if we ever had a functioning explainable-AI, results must confirm to the scholarly interpretations. In this regard we are following an early scholar's golden rule, "this knowledge constitutes your religion, so be wary of whom you take

${ }^{6}$ Mishkat al-Masabih 234 https://sunnah.com/mishkat:234 
your religion from" [1, p. 13]. This is not to diminish the practical utility of AI-based NLP, and the value of the AI-based NLP models would primarily be in their instrumental value in facilitating quicker research by being more scalable.

2) It is important to develop customized tools and an ecosystem around Qur'anic research. This is because using stock tools from other languages or those tools that have been designed for MSA may not provide reasonable results when applied to Qur'anic applications. This is also needed since mainstream language models trained on unrelated corpora is that they may contain unexpected biases. For instance, Abid et al. [98] have analyzed the state-of-the-art contextual language model GPT-3 and have shown that is shows persistent bias in tasks such as prompt completion, analogical reasoning, etc. These problems can be caused by biases in the data and in general ML-based NLP systems replicate and even amplify the biases in the training data and the presence of these errors requires human oversight for applications deploying these models [99]. This also underscores the previously-mentioned point that emphasized the need to have the results provided by the models vetted by experts for accuracy keeping in view the sensitive nature of the task of interpreting religious texts.

\section{Open IsSUes AND Future Research DiRections}

As compared to English NLP, Qur'anic NLP is still evolving. The important open issues and directions for future research are highlighted next.

1) For Qur'anic research, it is often useful to resort to nonQuranic corpus-in particular, the Hadith corpus and other classical Arabic Islamic books-since Qur'anic Arabic, or Classical Arabic, is different from Modern Standard Arabic and linguistic context of rare (gharib) words can be found by consulting the complementary resources. Future Qur'anic NLP research works should consider using these complementary data sources for developing better models and solutions.

2) A researcher working in Qur'anic NLP should be aware of the nuances of Qur'anic orthography and recitation. Prof. Abdel Haleem tracks the history of Qur'anic orthography in [100] and the agreement of Islamic scholars upon al-rasm al-'Uthmānī (the way of writing the text of the Qur'ân compiled during the time of the Caliph Uthman b. Affan), also referred to as rasm al-mushaf, as the standard written representation of the recited text of the Qur'an. The orthography of the Qur'an differs from the present, and it is hard to pin down to simple rules. For instance, all the 190 occurrences for "the Heavens"

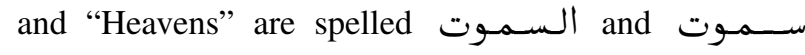
respectively, except once it is spelled السـموت [1, p. 145].

3) Very few existing works have considered multimodal NLP models trained on text as well as data from other
MUSHAF HAFS
WITH INDO-PAK
(NASTALITQ SCRIPT)

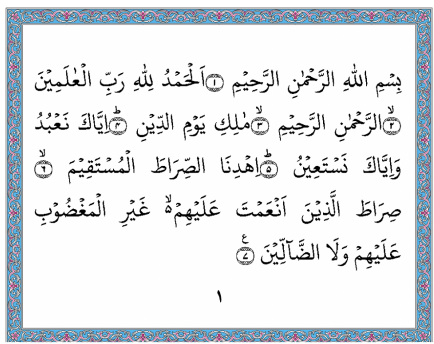

MUSHAF HAFS

WITH

MADANI SCRIPT
Fig. 13: The first chapter (Surah al-Fatiha) of the Qur'an (Hafs Reading) in South Asian style (Mushaf in Indo-Pak Nasta'liq Script) compared with the Mushaf in Madani script.

modalities including audio, images. It is important to explore what new diverse capabilities can emerge from using multimodal NLP models for Qur'anic research.

4) A lot of partial ontologies have been developed, which cover different concepts from the Qur'an. There is need to develop single consistent Ontology based on Qur'an and Hadith that covers all the concepts from the Qur'an. Such an ontology can help in knowledge extraction, question answering and search systems.

5) Techniques based on deep learning have not been much utilized for Qur'anic NLP. Recurrent Neural Networks (RNN) in the form of LSTM and BiLSTM, CNN, and AraBERT can be applied in various Qur'anic NLP tasks. Deep learning techniques can be useful in tasks where context remembrance is important and for the Qur'an, context is important while extracting knowledge.

6) Intelligent search systems are required for Qur'an, which should be able to answer the queries of people including Muslims and non-Muslims. Most of the current semantic and concept based search system are designed from topic perspective and not from a user perspective.

7) It is also well-known that multiple authenticated readings of the Qur'an have been reported from the Prophet Muhammad (PBUH) [1]. Such diversity cannot be ignored in any information retrieval process and accounting for this is yet another open issue and future research direction.

8) It is important to note that the Qur'anic scripting method used in the Indo-Pak subcontinent slightly differs to the style used in Arab countries even though they agree upon al-rasm al-'Uthmānī (see Figure 13). The Mushaf in Indo-Pak script relies upon the method of Imam Dani and Imam Ibn Dawud in writing of some alphabets and diacritics per the Uthmani script in a way different from their rendering in the Mushaf in Madani script [101]. A major issue with many existing systems is that they are not able recognize Qur'an text properly when expressed in Indo-Pak script.

For instance, a Qur'anic verse (1:2) is provided as input to the online Arabic text processing tool "Farasa" [102] for part of speech tagging, both the verses are tagged 


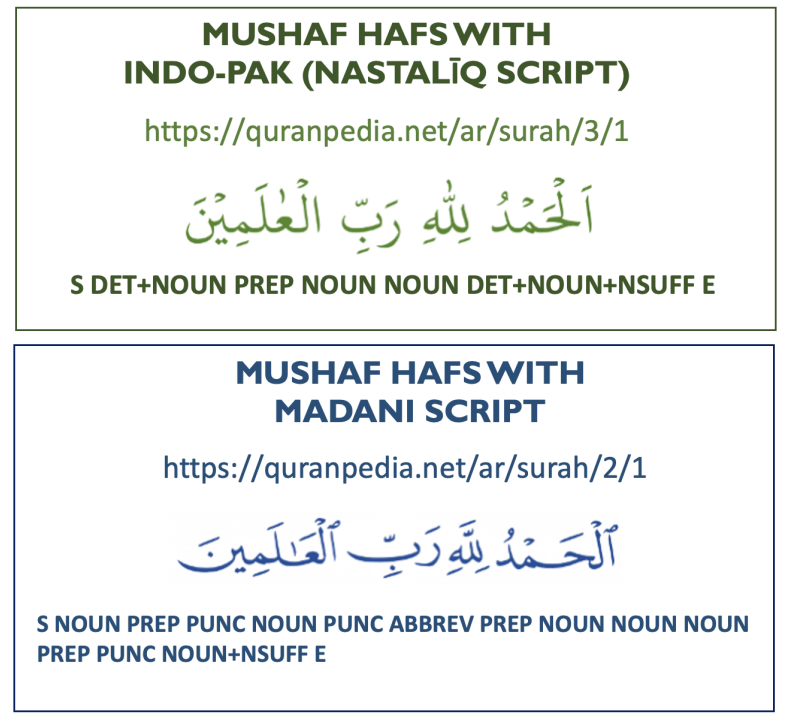

Fig. 14: Qur'anic verse (1:2) provided to the Farasa tool [102] for part of speech tagging resulting in inconsistent results. Poor results are shown for the Qur'an Mushaf with Nasta 'liq Script 13. (Legends: S: Start; DET: determiner; NOUN: noun; PREP: preposition; NSUFF: noun suffix; PUNC: puncutation; ABBREV: abbreviation; and E: End.)

completely differently (Figure 14). This highlights the problems that many Arabic NLP tools face when dealing with the different Qur'anic scripts.

\section{CONCLUSIONS}

Qur'anic NLP is an important area of research due to the importance of the Qur'an as the holy book of Muslims, whose global population touches 2 billion people. There has been a lot of recent interest in developing AI-based NLP tools for the Arabic language. However, the research on Qur'anic NLP is less mature compared to Arabic NLP, which is itself compared to a low-resource language for which limited tools and data is available when compared to works focusing on the English language. The challenges related to the Qur'an are quite complex owing to its rich style, its orthography, and most importantly its sacredness. Researchers are trying to overcome the challenges related to all the domains of NLP but still more effort is required. Based on these NLP technologies for Qur'an, many beneficial online applications and systems can be developed that will be helpful for both Muslims and non-Muslims. In this paper, we have provided a comprehensive survey of Qur'anic Arabic focused NLP techniques, tools, and applications. Apart from discussing the various techniques, tools, and applications that researchers have used in past research, we also provide a section on potential pitfalls and caveats and discuss open research issues and highlight promising directions for future work. This is the first comprehensive survey on this important topic and it will be useful as a reference for researchers and practitioners interested in working in this domain.

\section{FUNDING}

This research did not receive any specific grant from funding agencies in the public, commercial, or not-for-profit sectors.

\section{REFERENCES}

[1] M. M. Al-Azami, The History of the Qur'anic Text from Revelation to Compilation: A Comparative Study with the Old and New Testaments, 2nd ed. Turath Publishing, UK, 2020.

[2] A. M. Azmi, A. O. Al-Qabbany, and A. Hussain, "Computational and natural language processing based studies of hadith literature: A survey," Artificial Intelligence Review, vol. 52, no. 2, pp. 1369-1414, 2019.

[3] A. M. Azmi and E. A. Aljafari, "Universal web accessibility and the challenge to integrate informal arabic users: A case study," Universal Access in the Information Society, vol. 17, no. 1, pp. 131-145, 2018.

[4] J. A. Bellamy, "Two pre-Islamic Arabic Inscriptions revised: Jabal Ramm and Umm Al-Jimāl," Journal of the American Oriental Society, vol. 108, no. 3, pp. 369378, 1988.

[5] A. M. Azmi and A. Alsaiari, "A calligraphic based scheme to justify arabic text improving readability and comprehension," Computers in Human Behavior, vol. 39, pp. 177-186, 2014.

[6] A. Farghaly and K. Shaalan, "Arabic natural language processing: Challenges and solutions," ACM Transactions on Asian Language Information Processing (TALIP), vol. 8, no. 4, p. 14, 2009.

[7] S. A. Salloum, A. Q. AlHamad, M. Al-Emran, and K. Shaalan, "A survey of Arabic text mining," in Intelligent Natural Language Processing: Trends and Applications. Springer, 2018, pp. 417-431.

[8] A. M. Azmi and R. S. Almajed, "A survey of automatic arabic diacritization techniques," Natural Language Engineering, vol. 21, no. 3, pp. 477-495, 2015.

[9] N. Y. Habash, "Introduction to Arabic natural language processing," Synthesis Lectures on Human Language Technologies, vol. 3, no. 1, pp. 1-187, 2010.

[10] E. Atwell, N. Habash, B. Louw, B. Abu Shawar, T. McEnery, W. Zaghouani, and M. El-Haj, "Understanding the Quran: A new grand challenge for computer science and artificial intelligence," $A C M-B C S$ Visions of Computer Science 2010, 2010.

[11] A. Kammani and R. Safeena, "A review of Quranic computation for e-learning," International Journal of Web Science, vol. 2, no. 3, pp. 127-139, 2014.

[12] W. Zaghouani, "Critical survey of the freely available arabic corpora," Proceedings of the International Conference on Language Resources and Evaluation (LREC'2014), OSACT Workshop. Reykjavik, Iceland, vol. 26-31 May, 2014. [Online]. Available: http: //arxiv.org/abs/1702.07835

[13] E. Atwell, C. Brierley, K. Dukes, M. Sawalha, and A.B. Sharaf, "An artificial intelligence approach to Arabic and Islamic content on the Internet," in Proceedings of 
NITS 3rd National Information Technology Symposium. Leeds, 2011, pp. 1-8.

[14] M. Alhawarat, "Extracting topics from the holy Quran using generative models," International Journal of Advanced Computer Science and Applications, vol. 6, no. 12, pp. 288-294, 2015.

[15] R. Mohamed, M. Ragab, H. Abdelnasser, N. M. ElMakky, and M. Torki, "Al-bayan: A knowledge-based system for Arabic answer selection," in Proceedings of the 9th International Workshop on Semantic Evaluation (SemEval 2015), 2015, pp. 226-230.

[16] S. Chakroborty, A. Roy, and G. Saha, "Improved closed set text-independent speaker identification by combining mfcc with evidence from flipped filter banks," International Journal of Signal Processing, 2007.

[17] M. Gales and S. Young, The Application of Hidden Markov Models in Speech Recognition. Cambridge, UK: Now Publisher, 2007.

[18] C. Dimitrakakis and S. Bengio, "Phoneme and sentencelevel ensembles for speech recognition," EURASIP Journal on Audio, Speech, and Music Processing, 2011.

[19] K. Dukes and T. Buckwalter, "A dependency treebank of the Quran using traditional Arabic grammar," in 2010 the 7th International Conference on Informatics and Systems (INFOS). IEEE, 2010, pp. 1-7.

[20] K. Dukes, "The Quranic Arabic Corpus," https://corpus. quran.com/, 2009-2017.

[21] K. Dukes and N. Habash, "Morphological annotation of Quranic Arabic," in LREC, 2010.

[22] K. Dukes, E. Atwell, and A.-B. M. Sharaf, "Syntactic annotation guidelines for the Quranic Arabic dependency treebank," in LREC, 2010.

[23] K. Dukes, E. Atwell, and N. Habash, "Supervised collaboration for syntactic annotation of Quranic Arabic," Language resources and evaluation, vol. 47, no. 1, pp. 33-62, 2013.

[24] K. Dukes, E. Atwell, and A.-B. Sharaf, "Online visualization of traditional Quranic grammar using dependency graphs," in The Foundations of Arabic Linguistics Conference. Citeseer, 2010.

[25] R. Bentrcia, S. Zidat, and F. Marir, "An analytical study on the holy Quran based on the order of words in Arabic and conjunction," Malaysian Journal of Computer Science, vol. 31, no. 1, pp. 1-16, 2018.

[26] M. A. ELAffendi, I. Abuhaimed, and K. AlRajhi, "A simple Galois power-of-two real time embedding scheme for performing arabic morphology deep learning tasks," Egyptian Informatics Journal, pp. 35-43, 2021.

[27] M. A. Sherif and A.-C. Ngonga Ngomo, "Semantic Quran," Semantic Web, vol. 6, no. 4, pp. 339-345, 2015.

[28] H. S. Al-Khalifa, M. M. Al-Yahya, A. Bahanshal, and I. Al-Odah, "Semq: A proposed framework for representing semantic opposition in the holy Quran using semantic web technologies," in 2009 International Conference on the Current Trends in Information Technology (CTIT). IEEE, 2009, pp. 1-4.

[29] H. Afzal and T. Mukhtar, "Semantically enhanced con- cept search of the holy Quran: Qur'anic english wordnet," Arabian Journal for Science and Engineering, pp. 1-14, 2019.

[30] M. Shoaib, M. N. Yasin, U. K. Hikmat, M. I. Saeed, and M. S. H. Khiyal, "Relational wordnet model for semantic search in holy Quran," in 2009 International Conference on Emerging Technologies. IEEE, 2009, pp. 29-34.

[31] M. Alqahtani and E. Atwell, "A review of semantic search methods to retrieve information from the Qur'an corpus," 2015.

[32] M. Yunus, R. Zainuddin, and N. Abdullah, "Semantic query with stemmer for Quran documents results," in 2010 IEEE Conference on Open Systems (ICOS 2010). IEEE, 2010, pp. 40-44.

[33] — , "Visualizing Quran documents results by stemming semantic speech query," in 2010 International Conference on User Science and Engineering (i-USEr). IEEE, 2010, pp. 209-213.

[34] M. Al-Yahya, H. Al-Khalifa, A. Bahanshal, I. AlOdah, and N. Al-Helwah, "An ontological model for representing semantic lexicons: an application on time nouns in the holy Quran," Arabian Journal for Science and Engineering, vol. 35, no. 2, p. 21, 2010.

[35] R. Iqbal, A. Mustapha, and Z. Mohd. Yusoff, "An experience of developing Quran ontology with contextual information support," Multicultural Education \& Technology Journal, vol. 7, no. 4, pp. 333-343, 2013.

[36] M. Fernández-López, A. Gómez-Pérez, and N. Juristo, "Methontology: from ontological art towards ontological engineering," 1997.

[37] H. U. Khan, S. M. Saqlain, M. Shoaib, and M. Sher, "Ontology based semantic search in holy Quran," International Journal of Future Computer and Communication, vol. 2, no. 6, p. 570, 2013.

[38] B. B. M. Ali and M. Ahmad, "Al-Quran themes classification using ontology," Icoci. Cms. Net. My, vol. 74, pp. 383-389, 2013.

[39] A. Ta'a, Q. Abed, and M. Ahmad, "Al-Quran ontology based on knowledge themes," Journal of Fundamental and Applied Sciences, vol. 9, no. 5S, pp. 800-817, 2017.

[40] M. Alqahtani and E. Atwell, "Arabic Quranic search tool based on ontology," in International Conference on Applications of Natural Language to Information Systems. Springer, 2016, pp. 478-485.

[41] R. Ahmed and E. Atwell, "Developing an ontology of concepts in the Qur'an," International Journal on Islamic Applications in Computer Science And Technology, vol. 4, no. 4, pp. 1-8, 2016.

[42] M. Alqahtani and E. Atwell, "Aligning and merging ontology in al-Quran domain," 2016.

[43] A. Kammani and R. Safeena, "Towards a knowledgebased Quran translation: A conceptual model," in 2013 Taibah University International Conference on Advances in Information Technology for the Holy Quran and Its Sciences. IEEE, 2013, pp. 376-380.

[44] S. J. Putra, T. Mantoro, and M. N. Gunawan, "Text mining for indonesian translation of the Quran: A 
systematic review," in 2017 International Conference on Computing, Engineering, and Design (ICCED). IEEE, 2017, pp. 1-5.

[45] H. M. Hanum, Z. A. Bakar, and M. Ismail, "Evaluation of malay grammar on translation of al-Quran sentences using earley algorithm," in 2013 5th International Conference on Information and Communication Technology for the Muslim World (ICT4M). IEEE, 2013, pp. 1-4.

[46] B. Hammo, A. Sleit, and M. El-Haj, "Effectiveness of query expansion in searching the holy Quran," 2007.

[47] A. Al Gharaibeh, A. Al Taani, and I. Alsmadi, "The usage of formal methods in Quran search system," in Proceedings of international conference on information and communication systems, Ibrid, Jordan, 2011, pp. $22-24$.

[48] M. Alqahtani and E. Atwell, "Evaluation criteria for computational Quran search," International Journal on Islamic Applications in Computer Science And Technology, vol. 5, no. 1, pp. 12-22, 2017.

[49] S. A. Pitchay and F. Ridzuan, "A systematic review analysis for Quran verses retrieval," Journal of Engineering and Applied Sciences, vol. 100, no. 3, pp. 629634, 2016.

[50] M. N. Al-Kabi, G. Kanaan, R. Al-Shalabi, K. Nahar, and B. Bani-Ismail, "Statistical classifier of the holy Quran verses (fatiha and yaseen chapters)," Journal of Applied Sciences, vol. 5, no. 3, pp. 580-583, 2005.

[51] G. S. Hassan, S. K. Mohammad, and F. M. Alwan, "Categorization of 'holy Quran-tafseer'using k-nearest neighbor algorithm," International Journal of Computer Applications 11/2015, vol. 129, no. 12, pp. 1-6, 2015.

[52] M. Alshammeri, E. Atwell, and M. A. Alsalka, "Qur'anic topic modelling using paragraph vectors," in Conference: Intelligent Systems and Applications Proceedings of the 2020 Intelligent Systems Conference (IntelliSys), vol. 2. Springer, 2020, pp. 218-230.

[53] A. R. Yauri, R. A. Kadir, A. Azman, and M. A. A. Murad, "Quranic-based concepts: Verse relations extraction using manchester owl syntax," in 2012 International Conference on Information Retrieval \& Knowledge Management. IEEE, 2012, pp. 317-321.

[54] S. Saad, S. A. M. Noah, N. Salim, and H. Zainal, "Rules and natural language pattern in extracting Quranic knowledge," in 2013 Taibah University International Conference on Advances in Information Technology for the Holy Quran and Its Sciences. IEEE, 2013, pp. 381-386.

[55] M. A. Siddiqui, S. M. Faraz, and S. A. Sattar, "Discovering the thematic structure of the Quran using probabilistic topic model," in 2013 Taibah University International Conference on Advances in Information Technology for the Holy Quran and Its Sciences. IEEE, 2013, pp. 234-239.

[56] C. Brierley, M. Sawalha, and E. Atwell, "Tools for Arabic natural language processing: a case study in qalqalah prosody," in 9th International Conference on Language Resources and Evaluation. European Language Resources Association, 2014, pp. 283-287.
[57] N. J. Ibrahim, Z. Razak, Z. M. Yusoff, M. Y. I. Idris, E. M. Tamil, N. M. Noor, A. Rahman, and N. Naemah, "Quranic verse recitation recognition module for support in j-qaf learning: A review," Int. J. Comput. Sci. Netw. Secur., vol. 8, no. 8, pp. 207-216, 2008.

[58] A. H. Ahmed and S. M. Abdo, "Verification system for Quran recitation recordings," Int. J. Comput. Appl., vol. 163, no. 4, pp. 6-11, 2017.

[59] A. Qayyum, S. Latif, and J. Qadir, "Quran reciter identification: A deep learning approach," in 2018 7th International Conference on Computer and Communication Engineering (ICCCE). IEEE, 2018, pp. 492497.

[60] A. Mohammed, M. S. Sunar, and M. S. H. Salam, "Quranic verses verification using speech recognition techniques," Jurnal Teknologi, vol. 73, no. 2, 2015.

[61] N. Jamaliah Ibrahim, M. Yamani Idna Idris, Z. Razak, and N. Naemah Abdul Rahman, "Automated tajweed checking rules engine for Quranic learning," Multicultural Education \& Technology Journal, vol. 7, no. 4, pp. 275-287, 2013.

[62] A. Muhammad, Z. ul Qayyum, S. Tanveer, A. MartinezEnriquez, and A. Z. Syed, "E-hafiz: Intelligent system to help muslims in recitation and memorization of Quran," Life Science Journal, vol. 9, no. 1, pp. 534-541, 2012.

[63] M. Y. E. Amrani, M. Rahman, M. R. Wahiddin, and A. Shah, "Towards using CMU sphinx tools for the holy Quran recitation verification," 2015.

[64] B. Abro, A. B. Naqvi, and A. Hussain, "Qur'an recognition for the purpose of memorisation using speech recognition technique," in 2012 15th International Multitopic Conference (INMIC). IEEE, 2012, pp. 30-34.

[65] Y. Yekache, Y. Mekelleche, and B. Kouninef, "Towards Quranic reader controlled by speech," arXiv preprint arXiv:1204.1566, 2012.

[66] H. Tabbal, W. El Falou, and B. Monla, "Analysis and implementation of a Quranic verses delimitation system in audio files using speech recognition techniques," in 2006 2nd International Conference on Information \& Communication Technologies, vol. 2. IEEE, 2006, pp. 2979-2984.

[67] A. A. Al-Bakeri and A. A. Basuhail, "Asr for tajweed rules: Integrated with self-learning environments," International Journal of Information Engineering and Electronic Business, vol. 9, no. 6, p. 1, 2017.

[68] B. Putra, B. Atmaja, and D. Prananto, "Developing speech recognition system for Quranic verse recitation learning software," IJID (International Journal on Informatics for Development), vol. 1, no. 2, pp. 14-21, 2012.

[69] H. M. A. Tabbaa and B. Soudan, "Computer-aided training for Quranic recitation," Procedia-Social and Behavioral Sciences, vol. 192, pp. 778-787, 2015.

[70] H. Satori, M. Harti, and N. Chenfour, "Introduction to Arabic speech recognition using CMUSphinx system," arXiv preprint arXiv:0704.2083, 2007.

[71] M. Y. El Amrani, M. H. Rahman, M. R. Wahiddin, and A. Shah, "Building CMU sphinx language model 
for the holy Quran using simplified Arabic phonemes," Egyptian informatics journal, vol. 17, no. 3, pp. 305314, 2016.

[72] I. Ahsiah, N. Noor, and M. Idris, "Tajweed checking system to support recitation," in 2013 International Conference on Advanced Computer Science and Information Systems (ICACSIS). IEEE, 2013, pp. 189-193.

[73] A. Mohammed, M. S. B. Sunar, and M. S. H. Salam, "Recognition of holy Quran recitation rules using phoneme duration," in International Conference of Reliable Information and Communication Technology. Springer, 2017, pp. 343-352.

[74] M. Alrabiah, N. Alhelewh, A. Al-Salman, and E. Atwell, "An empirical study on the holy Quran based on a large classical Arabic corpus," International Journal of Computational Linguistics (IJCL), vol. 5, no. 1, pp. 1-13, 2014.

[75] S. K. Hamed and M. J. Ab Aziz, "A question answering system on holy Quran translation based on question expansion technique and neural network classification," JCS, vol. 12, no. 3, pp. 169-177, 2016.

[76] B. Hamoud and E. Atwell, "Evaluation corpus for restricted-domain question-answering systems for the holy Quran," International Journal of Science and Research, vol. 6, no. 8, pp. 1133-1138, 2017.

[77] K. N. ElSayed, "An Arabic natural language interface system for a database of the holy Quran," International Journal of Advanced Research in Artificial Intelligence, vol. 4, no. 7, pp. 9-14, 2015.

[78] A. Alshareef and A. El Saddik, "A Quranic quote verification algorithm for verses authentication," in 2012 International Conference on Innovations in Information Technology (IIT). IEEE, 2012, pp. 339-343.

[79] I. Alsmadi and M. Zarour, "Online integrity and authentication checking for Quran electronic versions," Applied Computing and Informatics, vol. 13, no. 1, pp. 38-46, 2017.

[80] W. Zaghouani and K. Dukes, "Can crowdsourcing be used for effective annotation of Arabic?" in LREC, 2014, pp. 224-228.

[81] A.-B. Sharaf and E. Atwell, "QurSim: A corpus for evaluation of relatedness in short texts," in Proceedings of the Eighth International Conference on Language Resources and Evaluation (LREC'12). Istanbul, Turkey: European Language Resources Association (ELRA), May 2012, pp. 22952302. [Online]. Available: http://www.lrec-conf.org/ proceedings//rec2012/pdf/190_Paper.pdf

[82] M. Palmer, D. Gildea, and P. Kingsbury, "The Proposition Bank: An annotated corpus of semantic roles," Computational Linguistics, vol. 31, no. 1, pp. 71-106, 2005. [Online]. Available: https://www.aclweb. org/anthology/J05-1004

[83] W. Zaghouani, A. Hawwari, and M. Diab, "A pilot propbank annotation for Quranic Arabic," in Proceedings of the NAACL-HLT 2012 Workshop on Computational Linguistics for Literature, 2012, pp. 78-83.

[84] M. Palmer, O. Babko-Malaya, A. Bies, M. Diab,
M. Maamouri, A. Mansouri, and W. Zaghouani, "A pilot Arabic Propbank," in Proceedings of the Sixth International Conference on Language Resources and Evaluation (LREC'08). Marrakech, Morocco: European Language Resources Association (ELRA), May 2008. [Online]. Available: http://www.lrec-conf. org/proceedings/lrec2008/pdf/880_paper.pdf

[85] K. Dukes and T. Buckwalter, "A dependency treebank of the Quran using traditional Arabic grammar," in 2010 The 7th International Conference on Informatics and Systems (INFOS), 2010, pp. 1-7.

[86] T. Buckwalter, "Buckwalter Arabic Morphological Analyzer Version 2.0," https://catalog.ldc.upenn.edu/docs/ LDC2004L02/readme.txt, 2004.

[87] A. B. Muhammad, "Annotation of conceptual coreference and text mining the qur'an," September 2012. [Online]. Available: http://etheses.whiterose.ac.uk/4160/

[88] "SPARQL Query Language for RDF," https://www.w3. org/TR/rdf-sparql-query/, 2008.

[89] "ISO/IEC 9075-1:2008, Information technology Database languages - SQL - Part 1: Framework (SQL/Framework)," https://www.iso.org/standard/ 45498.html.

[90] "Protégé," https://protegewiki.stanford.edu/wiki/ Protege, 2004.

[91] D. L. Rubin, H. Knublauch, R. W. Fergerson, O. Dameron, and M. A. Musen, "Protégé-owl: Creating ontology-driven reasoning applications with the web ontology language." AMIA, 2005.

[92] N. F. Noy and M. A. Musen, "The prompt suite: interactive tools for ontology merging and mapping," International journal of human-computer studies, 2003.

[93] "Overview of the CMUSphinx toolkit," https:// cmusphinx.github.io/wiki/tutorialoverview/.

[94] "Amazon mechanical turk," https://www.mturk.com/.

[95] H. Zarrabi-Zadeh, "Tanzil," http://tanzil.net/, 20072021.

[96] H. H. Yusuf, "The importance of being ambiguous or the sin tax of ignoring syntax," https://tinyurl.com/ y7nge9j6, 2011.

[97] D. Hofstadter, "The shallowness of Google Translate," https://www.theatlantic.com/technology/archive/2018/ 01/the-shallowness-of-google-translate/551570/, 2018.

[98] A. Abid, M. Farooqi, and J. Zou, "Persistent AntiMuslim Bias in Large Language Models," arXiv preprint arXiv:2101.05783, 2021.

[99] D. Jurafsky and J. H. Martin, "Speech and language processing, 3rd edition (draft)," https://web.stanford. edu/ jurafsky/slp3/, Reference Date: 1 February, 2021.

[100] A. M. Haleem, "Qur'ānic orthography: The written representation of the recited text of the qur'ān," Islamic Quarterly, vol. 38, no. 3, p. 171, 1994.

[101] H. M. Ajmal and M. I. Lodhi, "Methods of the 'Uthmanic Script of the Quran-A Special Study of Pakistani Printed Masahif," Peshawar Islamicus, vol. 9, no. 1, 2018.

[102] "Farasa," https://farasa.qcri.org/. 